\title{
Measured ice nucleating particle concentrations improve the simulation of mid-level mixed-phase clouds over the high-latitude Southern Ocean
}

\author{
É. Vignon ${ }^{1}$, S. P. Alexander ${ }^{2,3}$, P. J. DeMott ${ }^{4}$, \\ G. Sotiropoulou ${ }^{5,6}$, F. Gerber ${ }^{7,8}$, T. C. J. Hill ${ }^{4}$, R. Marchand ${ }^{9}$, \\ A. Nenes ${ }^{5,10}$ and A. Berne ${ }^{1}$ \\ ${ }^{1}$ Environmental Remote Sensing Laboratory (LTE), École Polytechnique Fédérale de Lausanne (EPFL), \\ Lausanne, Switzerland \\ ${ }^{2}$ Australian Antarctic Division, Kingston, Tasmania, Australia \\ ${ }^{3}$ Australian Antarctic Program Partnership, Institute for Marine and Antarctic Science, University of \\ Tasmania, Hobart, Australia \\ ${ }^{4}$ Department of Atmospheric Science, Colorado State University, Fort Collins \\ ${ }^{5}$ Laboratory of Atmospheric Processes and their Impacts (LAPI), Ecole Polytechnique Fédérale de \\ Lausanne (EPFL), Lausanne, Switzerland \\ ${ }^{6}$ Department of Meteorology and Bolin Center for Climate Research, Stockholm University, Stockholm, \\ Sweden \\ ${ }^{7}$ Laboratory of Cryospheric Sciences, School of Architecture, Civil and Environmental Engineering, École \\ Polytechnique Fédérale de Lausanne (EPFL), Lausanne, Switzerland \\ ${ }^{8}$ WSL Institute for Snow and Avalanche Research SLF, Davos, Switzerland \\ ${ }^{9}$ Department of Atmospheric Sciences, University of Washington, Seattle, WA, USA \\ ${ }^{10} \mathrm{ICE}-\mathrm{HT}$, Foundation for Research and Technology Hellas (FORTH), Patras, Greece \\ Key Points: \\ - WRF simulations of mixed-phase clouds over the high-latitude Southern Ocean \\ are evaluated with remotely-sensed data from the MARCUS ; \\ - Accounting for the low concentration of ice nucleating particles is critical to sim- \\ ulate thin supercooled liquid water layer at cloud top; \\ - Further parameterization developments targeting the convection at cloud top are \\ needed to reproduce the turbulence-microphysics interplay.
}

Corresponding author: Étienne Vignon, etienne.vignon@epfl.ch 


\section{Abstract}

Climate models exhibit major radiative biases over the Southern Ocean owing to a poor representation of mixed-phase clouds. This study uses the remote-sensing dataset from the Measurements of Aerosols, Radiation and Clouds over the Southern Ocean (MARCUS) campaign to assess the ability of the Weather Research and Forecasting (WRF) model to reproduce frontal clouds off Antarctica. It focuses on the modeling of thin midlevel supercooled liquid water layers which precipitate ice. The standard version of WRF produces almost fully glaciated clouds and cannot reproduce cloud top turbulence. Our work demonstrates the importance of adapting the ice nucleation parameterization to the pristine austral atmosphere to reproduce the supercooled liquid layers. Once simulated, droplets significantly impact the cloud radiative effect by increasing downwelling longwave fluxes and decreasing downwelling shortwave fluxes at the surface. The net radiative effect is a warming of snow and ice covered surfaces and a cooling of the ocean. Despite improvements in our simulations, the local circulation related to cloud-top radiative cooling is not properly reproduced, advocating for the need to develop a parameterization for top-down convection to capture the turbulence-microphysics interplay at cloud top.

\section{Plain Language Summary}

Among the major shortcomings of climate models is a poor representation of clouds over the Southern Ocean. Thanks to new measurements from the Measurements of Aerosols, Radiation and Clouds over the Southern Ocean campaign that took place aboard the Aurora Australis ice breaker, we can now better assess the ability of models to represent clouds off Antarctica. In particular, we focus here on clouds that are mostly composed of ice crystals but that are topped by a thin layer of so-called 'supercooled' liquid droplets that form at temperatures below zero Celsius. While the standard version of the model produces almost fully-glaciated clouds (clouds composed only of ice), we show that by adapting the formulation of ice crystal formation to the very pristine atmospheric conditions peculiar to the Southern Ocean it is possible to successfully reproduce thin layers of supercooled liquid droplets observed in mixed-phase clouds. The latter significantly changes how much sunlight these clouds reflect to space, which is critical to understanding the climate. Compared to ice crystals, liquid droplets tend to re- 
flect more solar energy towards space and at the same time, they enhance the cloud infrared emission towards the surface of the Antarctic ice sheet.

\section{Introduction}

The Southern Ocean is a region where radiative biases in models involved in the 5th Coupled Model Intercomparison Project (CMIP) are amongst the largest globally (Flato \& coauthors, 2013; Hyder et al., 2018). Such biases have been attributed to a poor representation of clouds that cover more than $80 \%$ of the total Southern Ocean surface on average (Mace, 2010) and that are mostly of mixed-phase composition, i.e. containing both ice crystals and supercooled liquid water (SLW). Low-level mixed-phase clouds are the primary source of those biases (Bodas-Salcedo et al., 2014) but mid-level clouds associated with the passage of warm fronts are also partly responsible (Mason et al., 2014). While the climate sensitivity in some of recent climate models highly depends on Southern Ocean clouds (Gettelman et al., 2019; Zelinka et al., 2020), substantial shortcomings regarding the simulation of mixed-phase clouds persist (e.g., Lenaerts, Van Tricht, Lhermitte, \& L'Ecuyer, 2017; Kawai et al., 2019).

The SLW amount in austral mixed-phase clouds is particularly high in summer, at low altitude and over ice-free surfaces (Listowski et al., 2019). Highly reflective SLW droplets substantially enhance the cloud albedo and therefore the amount of shortwave radiation reflected towards space (Kay et al., 2016; Protat et al., 2017). By significantly increasing the cloud optical depth, the amount of SLW in clouds is also critical for their radiative forcing in the infrared spectrum.

Atmospheric models generally struggle to reproduce the albedo (Bodas-Salcedo et al., 2014, 2016; Varma et al., 2020) and the surface longwave radiative flux associated with frontal clouds over the Southern Ocean, that can be further advected over the Antarctic ice sheet (King et al., 2015; Listowski \& Lachlan-Cope, 2017; Vignon et al., 2018; Hines et al., 2019; Ricaud et al., 2020). This is highly problematic for reproducing the net cloud radiative forcing at the ice sheet surface and for predicting melting events associated with oceanic intrusions of warm, moist and cloudy air masses (Nicolas et al., 2017; Wille et al., 2019; Silber et al., 2019; Gilbert et al., 2020). Along the Antarctic edge, SLW is also a key ingredient for precipitation generation and growth, through riming of snowflakes 
(Grazioli et al., 2017; Vignon, Besic, et al., 2019) and through secondary ice production processes (Young et al., 2019; Sotiropoulou et al., 2020).

In mixed-phase clouds, SLW is thermodynamically unstable and depletes through transfer of water vapor towards ice crystals by the Wegener-Bergeron-Findeisen (WBF) process. The presence of SLW in mixed-phase clouds for more than a few hours is thus explained by a complex interplay between radiative exchanges, turbulent mixing and microphysics (Morrison et al., 2012; A. V. Korolev \& Mazin, 2003). A body of literature has documented this a priori surprising resilience of SLW in cold clouds, especially in boundary-layer clouds in the Arctic (see reviews in A. Korolev et al., 2017 and Andronache \& coauthors, 2017). In particular, for typical mixed-phase stratocumulus and altocumulus found at mid- or high latitudes (Hogan et al., 2003; P. A. Barrett et al., 2020), the SLW resilience results from the following mechanism. At cloud top, the radiative cooling of the air - and to a second extent the sublimation and evaporation of hydrometeors - drive a top down turbulent mixing that in turn generates compensating updrafts. If the updrafts are intense enough (A. V. Korolev \& Mazin, 2003), the relative humidity can exceed saturation with respect to liquid through air adiabatic cooling during ascent. Cloud droplets thus form and are advected upward, thereby forming a thin - a few hundred meter deep - layer of SLW at cloud top, below which ice crystals grow through the WBF process and possibly other mechanismes like riming and then sediment. SLW formation is further favored in conditions of high concentrations of cloud condensation nuclei (CCN) and low concentrations of ice nucleating particles (INPs).

The difficulty for atmospheric models to simulate SLW in austral mixed-phase clouds - be they either low-level stratocumulus or mid-level clouds - mostly lies in: i) their too coarse vertical resolution since SLW layers are a few tens or hundreds meters deep, i.e., often thinner than model layers in common atmospheric models (A. I. Barrett et al., 2017b); ii) in a deficient representation of the turbulent mixing at the sharp cloud top boundary (Sotiropoulou et al., 2016) and iii) inadequate parameterizations or tuning of cold microphysical processes for the typical conditions encountered at high latitude (Forbes \& Ahlgrimm, 2014; A. I. Barrett et al., 2017a; Furtado et al., 2016; Listowski \& LachlanCope, 2017). The atmosphere above the Southern Ocean being particularly pristine, with INPs in the boundary layer that mostly originate from sea spray aerosols only (DeMott et al., 2016; McCluskey et al., 2018; Uetake et al., 2020), many current model formulations for ice nucleation may be inadequate. Such formulations were indeed mostly de- 
veloped for mid-latitude conditions where much higher concentrations of INPs are typically present. They can potentially lead to substantial underestimation of SLW droplets in clouds and hence major radiative biases in models (Vergara-Temprado et al., 2018). In addition, previously underappreciated processes like secondary ice production through ice particle break-up also seem particularly critical to explain the concentration of ice crystals in clouds over the Antarctic coast (Young et al., 2019; Sotiropoulou et al., 2020).

During the austral summer 2017-2018, the Measurement of Aerosols, Radiation and Clouds over the Southern Ocean (MARCUS) campaign was conducted aboard the Australian ice-breaker Aurora Australis as the ship made three return crossings of the Southern Ocean from Hobart to East Antarctica in order to resupply the three Australian Antarctic stations.

The MARCUS campaign offers a unique dataset to evaluate the ability of atmospheric models to represent frontal mixed-phase clouds adjacent to the Antarctic coast and to foster the development, evaluation and tuning of adequate microphysics and turbulence parameterizations in models.

In this study, we make use of those data to evaluate and improve the representation of austral mixed-phase clouds in the Weather Research and Forecasting (WRF) model. We focus on clouds associated with the passage of a warm front above Mawson station $\left(67.6^{\circ} \mathrm{S}, 62.9^{\circ} \mathrm{E}\right.$, green dot in Figure 1) between the 14 and the 16 February 2018 . We pay particular attention to the challenging representation of SLW layers at the top of mid-altitude clouds preceding and following the front. Beyond the WRF evaluation, the aim of the paper is to identify priorities and propose pathways for parameterization development and tuning which can assist cloud modeling over the Southern Ocean.

\section{Meteorological setting, observations and simulations}

\subsection{Remotely-sensed and in situ observations from the Aurora Australis}

A comprehensive suite of instrumentation from the second Atmospheric Radiation Measurement (ARM) Mobile Facility (McFarquhar et al. 2020, submitted to BAMS) was deployed aboard the ship. A vertically-pointing W-band (95 GHz) Doppler cloud radar (MWACR) sampling every $2 \mathrm{~s}$ and set-up on a stabilizing platform provided vertical profiles of reflectivity, Doppler velocity and spectral width. The reflectivity measurements were calibrated following Kollias et al. (2019). During the study case period, the ship 


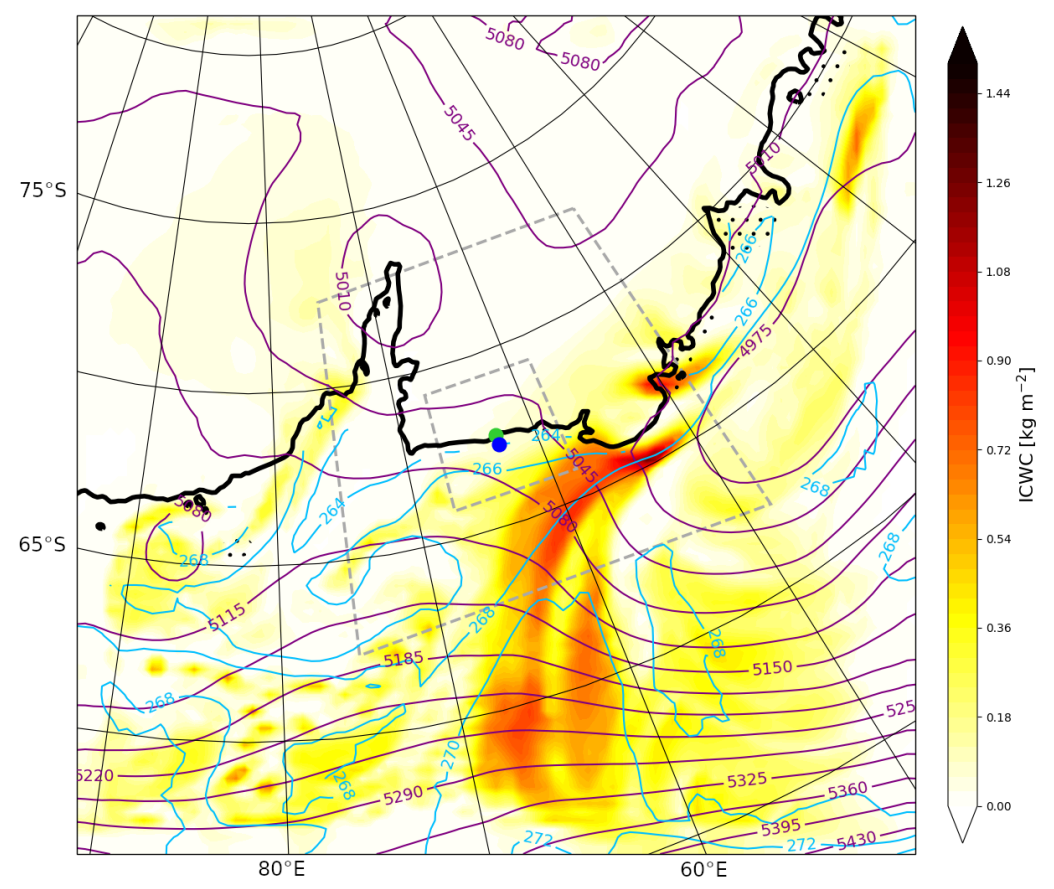

Figure 1. Map of synoptic conditions around Mawson station at 00 UTC, 15 February 2018, from the ctrl Polar WRF simulation (27-km resolution domain). The purple (resp. cyan) contours show the $500 \mathrm{hPa}$ geopotential height in $\mathrm{m}$ (resp. the $900 \mathrm{hPa}$ temperature above the Ocean in K). The color shading shows the vertically integrated condensed water content (ICWC, sum of cloud liquid droplets, cloud ice crystals, snow, rain and graupel species). Dashed grey lines delimit the $9-\mathrm{km}$ and $3-\mathrm{km}$ resolution domains. Regions where the sea ice concentration is greater than 0.5 are marked with small black dots. The green circle locates Mawson station while the blue circle indicates the position of the Aurora Australis at 00 UTC, 15 February 2018. 
was in very calm waters thanks to offshore ice that damped sea swells. Subsequently, the radar Doppler velocity uncertainty due to ship's heave is very low (the standard deviation of the heave velocity during the three days of interest is lower than $0.01 \mathrm{~m} \mathrm{~s}^{-1}$ ). From the processing of Doppler velocity time series, it is possible to estimate the dissipation rate $\epsilon$ of turbulent kinetic energy (TKE) within the cloud (see Sect. 1 of the supporting information). A micro-pulse lidar (MPL) with a polarization sensitive system and a 5-min temporal resolution allowed for the identification of SLW layers following Alexander and Protat (2018). Radiosondes were launched every six hours - 0530, 1130, 1730, 2330 UTC (Sato, Inoue, Alexander, McFarquhar, \& Yamazaki, 2018) - and standard meteorological variables were also measured on the ship, including downward shortwave and longwave radiative fluxes. The liquid water path (LWP) was estimated from microwave radiometer data following Marchand et al. (2003).

Ice nucleating particles were also measured from aerosol filter collections, as in prior ship campaigns (McCluskey et al., 2018). Cumulative temperature spectra of the number concentration of INPs active via immersion freezing were derived from data collected on the freezing of dilute (purified) water droplet suspensions of collected aerosols using the Colorado State University ice spectrometer instrument system (McCluskey et al., 2018). Details of the instrument methods, clean protocols, calculation of cumulative INPs per volume of suspension, conversion of these to numbers per liter of sampled air versus temperature, and calculation of confidence intervals (95\%) are discussed in DeMott et al. (2018). Filter samples were 24 or 48 hour collections, representing approximately 21 or $42 \mathrm{~m}^{3}$ of air, respectively. Temperature spectra (six represented) of the INP concentrations measured close to Mawson station during MARCUS are plotted in Figure 2d.

\subsection{WRF simulations}

This work is based on the version 4.1.1 of the WRF model. The simulation configuration follows that used by Vignon, Besic, et al. (2019). The model has been run with a downscaling method where a $27-\mathrm{km}$ resolution parent domain contains a 9-km resolution domain which itself contains a $102 \times 102 \mathrm{~km}^{2}$ nest at a $3-\mathrm{km}$ resolution (see Figure 1). Note that achieving a $3-\mathrm{km}$ resolution is needed to correctly capture the dynamics of Antarctic katabatic winds and in particular their coastal transition (Vignon, Traullé, \& Berne, 2019; Vignon et al., 2020). All WRF domains have been built with the same polar stereographic projection and they are centered over Mawson station. The nesting 

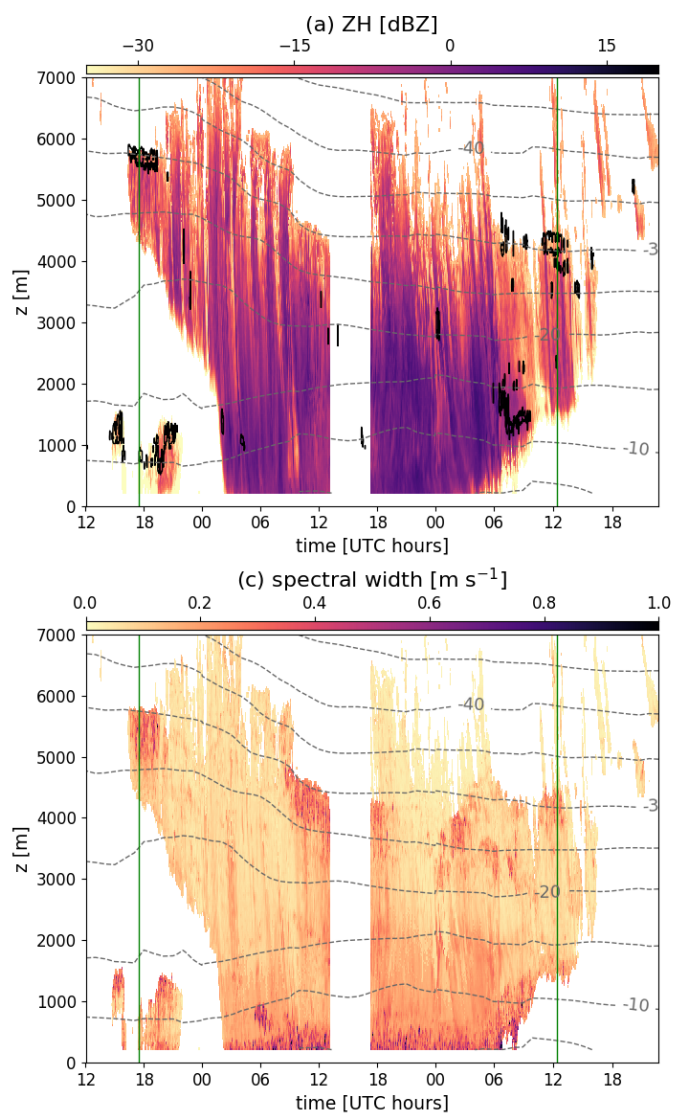

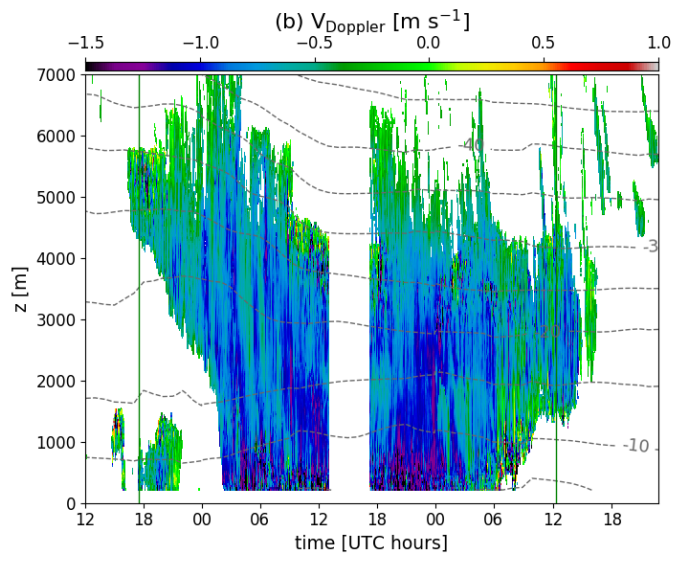

(d) INP concentration

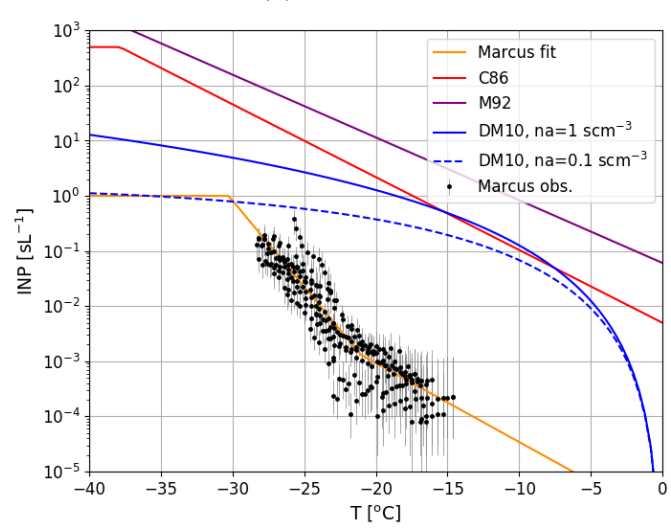

Figure 2. Panel a, b, c: Time height plots of the radar reflectivity ZH, Doppler velocity $\mathrm{V}_{\text {Doppler }}$ and Doppler spectral width respectively, measured by the MWACR above the ship between the 14 and 16 February 2018. Grey contours indicate the air temperature $\left(5^{\circ} \mathrm{C}\right.$ intervals $)$ from the ERA5 reanalyses. Vertical green lines indicate the two specific times analyzed in Figure 6. In panel a, black outlines locate regions where the MPL detects SLW. Panel d: Temperature spectrum of the INP concentration. Black dots show measurements off Mawson station during the present MARCUS case study. Errorbars represent the $95 \%$ confidence intervals calculated in the same manner as in McCluskey et al. (2018). The orange line shows a fit on the data (see eq. 1). The red line shows the relationship from Cooper (1986) (C86). The purple line shows eq. 2.6 in Meyers et al. (1992) (M92). Blue lines show the DeMott et al. (2010)'s relationship for two extreme values of the concentration of aerosols larger than $0.5 \mu \mathrm{m}$ (na) which commonly ranges between 0.1 and $1 \mathrm{scm}^{-3}$ 


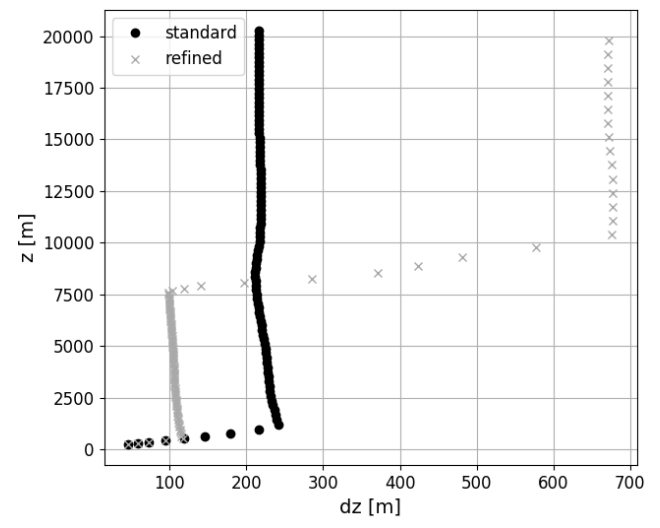

Figure 3. Mean altitude of WRF $\eta$ levels $(z)$ plotted versus the corresponding layer thickness $(d z)$. Black circles refer to the 'standard' 96-level grid. Grey crosses refer to the 'refined' 96-level grid with thinner layers in the low- and mid-troposphere.

is one way i.e. no information is passed in return from one domain to its parent. Lateral forcings, sea ice concentration, sea surface temperature and initial conditions are from the ERA5 reanalysis (Hersbach et al., 2020). The topography is from the 1-km resolution Reference Elevation Model of Antarctica dataset (Howat et al., 2019). The model is run with 96 vertical levels up to $50 \mathrm{hPa}$. The so-called 'standard' grid (black circles in Figure 3) is automatically generated by WRF after setting the vertical level number. It shows layer thicknesses between 200 and $250 \mathrm{~m}$ in the mid-troposphere. Using 1D simulations of mixed-phase altocumulus, A. I. Barrett et al. (2017b) stress that a resolution of at least $100 \mathrm{~m}$ is needed to sustain a SLW layer at cloud top. A so-called 'refined' grid has thus been set-up to refine the vertical resolution in the mid-troposphere to about 100 $\mathrm{m}$ at the expense of the representation of the stratosphere (grey crosses in Figure 3).

Simulations start on February, 14201800 UTC corresponding to a $17 \mathrm{~h}$ spin-up time before the arrival of the first frontal clouds above the ship location. To allow for a concomitant comparison between in situ observations and simulations and to ensure a realistic synoptic dynamics in the model, the $27-\mathrm{km}$ resolution domain has been nudged above the boundary layer towards ERA5 reanalysis for zonal and meridional wind speed, with a relaxation time scale of $6 \mathrm{~h}$. The nudging only helps provide the best lateral forcing for the free 9-km and 3-km resolution domains. The physics options employed throughout the study include the new version of the Rapid Radiative Transfer Model for Gen- 
eral Circulation Models radiation scheme for longwave and shortwave spectra, the Noah land surface model with adaptations by Hines and Bromwich (2008) and the Mellor-YamadaNakanishi-Niino (MYNN) planetary boundary layer scheme coupled with its associated surface layer scheme. For the domains with a resolution greater than or equal to $9 \mathrm{~km}$, the Kain-Fritsch cumulus scheme has been activated. For a proper comparison with MWACR data, W-band radar reflectivity from WRF outputs has been calculated by means of the Cloud Resolving Model Radar Simulator (CR-SIM, Oue et al., 2020) version 3.1. CRSIM uses the T-matrix method for computing the scattering properties of cloud water, cloud ice, rain, snow, graupel, and hail hydrometeors. In this study, CR-SIM has been configured as a virtual MWACR vertically profiling radar - with a frequency of $94 \mathrm{GHz}$ (close to the $95 \mathrm{GHz}$ frequency of the real instrument) and similar radar beamwidth and range resolution - that follows the track of the Aurora Australis.

\subsubsection{Microphysical scheme setting}

We employ the microphysical parameterization from Morrison et al. (2005) which was shown to produce more realistic amounts of liquid water in Antarctic clouds compared to less advanced WRF parameterizations and also produces realistic precipitation in coastal Adélie Land (Listowski \& Lachlan-Cope, 2017; Hines et al., 2019; Vignon, Besic, et al., 2019). The scheme has a single-moment treatment of cloud droplets and a doublemoment treatment of cloud ice, rain drops, snow and graupel particles. The activation of cloud droplets on CCN is not parameterized in the Morrison scheme (except when coupling WRF with its chemical module) and the droplet number concentration is a constant number. We set it to $100 \mathrm{~cm}^{-3}$, a value that reasonably concurs with other studies over the Antarctic coast and with CCN measurements collected aboard the Aurora Australis during MARCUS (see Sect. 2 of the supporting information).

Regarding primary ice production, tendencies of ice number and mass concentrations associated with homogeneous freezing of droplets (at temperatures $\leq 233.15 \mathrm{~K}$ ) and three heterogeneous ice nucleation mechanisms are parameterized. In our control simulations, immersion freezing of cloud droplets and raindrops is taken into account following the stochastic approach of Bigg (1953). Contact freezing is parameterized as a flux of contact INP to cloud droplets and the number of contact nuclei is given by Meyers et al. (1992) (M92). Deposition/condensation freezing nucleation is parameterized as a nudging term towards an INP concentration predicted as a function of temperature fol- 
lowing Cooper (1986) (C86). Although our control (ctrl) simulation has been run with this configuration, the heterogeneous nucleation schemes are questionable for our study case. First, Bigg (1953)'s scheme based on laboratory data does not specifically account for ice nuclei and it was shown to be poorly reliable for polar conditions (e.g., de Boer, Hashino, Tripoli, \& Eloranta, 2013; Paukert \& Hoose, 2014). Second, except at temperatures warmer than about $-10^{\circ} \mathrm{C}$ where contact freezing dominates, the ice production in the ctrl WRF simulation during MARCUS is dominated by the deposition/condensation freezing nucleation scheme, but especially at temperatures lower than $-15^{\circ} \mathrm{C}$ (see Figure S2). Immersion freezing nucleation is thought to be the dominant nucleation mode in most mixed-phase clouds (Andronache \& coauthors, 2017). It is likely that this mode is represented in the mixed-phase cloud observations from C86 that are parameterized as deposition/condensation freezing in WRF, but the number concentrations are representative of the mid-latitude, continental regions where the observations were primarily collected. Indeed, the INP concentration prescribed in the C86's deposition nucleation scheme is much higher than the measured INP concentration in the immersion freezing mode for the Mawson region at the time of this case study (Figure 2d). This excess of INP also impedes the generation of SLW and of all subsequent freezing processes.

As underlined by O'Shea et al. (2017), C86 and M72 parameterizations were developed for continental conditions in which the INP concentrations are several orders of magnitude higher than in the pristine atmosphere above the Southern Ocean (DeMott et al., 2016; Kanji et al., 2017). DeMott et al. (2010) further developed an INP parameterization using not only the temperature but also the concentration of aerosols. This parameterization better predicts the ice crystal number concentration present in clouds over the Antarctic Peninsula than C86 or M92 (Listowski \& Lachlan-Cope, 2017). However it overestimates the INP concentration off Mawson station (Figure 2d) and using it instead of C86's formulation only - as in Young et al. (2019) - decreases the ice nucleation rate but maintains ice formation at temperatures lower than $-20^{\circ} \mathrm{C}$ (see Figure S2).

We thus replaced all the heterogeneous nucleation parameterizations in the Morrison microphysical scheme with a unique empirical one - reflecting immersion freezing - in the manner of Paukert and Hoose (2014). Note that the Bigg's parameterization is nonetheless kept active for the freezing of big rain drops. INP measurements during MARCUS have first been fitted with the following equation (see orange line in Figure 2d): 


$$
\log \left(N_{I N P}\right)= \begin{cases}-0.14\left(T-T_{2}\right)-2.88, & \text { if } T>T_{1} \\ -0.31\left(T-T_{1}\right)-2.88, & \text { if } T_{2} \leq T \leq T_{1} \\ 0.0 & \text { if } T<T_{2}\end{cases}
$$

with $N_{I N P}$ the INP number concentration in $\mathrm{sL}^{-1}, T$ the temperature in ${ }^{\circ} \mathrm{C}, T_{1}=$ $-21.06{ }^{\circ} \mathrm{C}$ and $T_{2}=-30.35{ }^{\circ} \mathrm{C}$. INP measurements were performed at $T>-28{ }^{\circ} \mathrm{C}$ questioning extrapolation of the curve at very low temperatures. Here, we taper the exponential increase with decreasing temperature and constrain $N_{I N P}$ not to exceed $1 \mathrm{sL}^{-1}$, a value close to the prediction from the DeMott et al. (2010)'s parameteterization for low aerosol concentrations (Figure 2d). Setting such a threshold is motivated by recent measurements during the CAPRICORN campaign over the Southern Ocean in McCluskey et al. (2018). The authors revealed that the INP concentration in the immersion mode no longer increases with decreasing temperature - staying below $1 \mathrm{sL}^{-1}$ when temperature is lower than about $-28^{\circ} \mathrm{C}$. Similar behavior has been observed for other geographical contexts (Kanji et al., 2017).

Then, the ice crystal production term follows the equation:

$$
\left.\frac{d N_{i}}{d t}\right|_{\text {nucleation }}= \begin{cases}\frac{N_{I N P}-\left(N_{i}+N_{s}+N_{g}\right)}{\Delta t}, & \text { if } N_{I N P}>N_{i}+N_{s}+N_{g} \\ 0.0 & \text { otherwise }\end{cases}
$$

where $\Delta t$ the model timestep and $N_{i}, N_{s}$ and $N_{g}$ the number concentration of ice crystals, snowflakes and graupel particles respectively. As this empirical parameterization reflects immersion freezing, the produced mass of cloud ice is removed from cloud liquid water. It is worth noting that this new ice nucleation parameterization is based on INP measurements in the boundary-layer off Mawson station. 5-day back-trajectories revealed that the air parcels arriving in the mid-troposphere above the ship during the study case mostly originate from the north and west of the station and has been lifted from the marine boundary-layer in the vicinity of the station (see Figure S3). The present nucleation scheme should therefore be reasonably valid in both boundary-layer and midlevel frontal clouds.

Furthermore, the Morrison scheme accounts for secondary ice production through the rime-splintering process (Hallett-Mossop) in the $\left[-8^{\circ} \mathrm{C},-3^{\circ} \mathrm{C}\right]$ temperature range. However, Young et al. (2019) show that this process should be artificially enhanced by 
a factor of 10 to reproduce the observed ice crystal concentrations over the Weddell Sea. Sotiropoulou et al. (2020) suggest that it may be due to the absence of parametrization for the secondary ice production through ice particle break-up after hydrometeor collision. By default in our simulations we do not activate a parameterization of collisional break-up but complementary sensitivity experiments have been carried out.

\subsubsection{Cloud top turbulence parameterization}

SLW layers at cloud top are a few hundreds of meters deep - i.e. of comparable width or even thinner than common atmospheric model layers - and they are characterized by a vigorous turbulence that is critical to generate and maintain the SLW. This turbulence should be represented in models. However, cloud tops are regions of sharp vertical gradients of atmospheric properties which are difficult to simulate with the current vertical resolutions of models. The turbulent mixing at cloud top - or entrainment - has been and is still an active subject of research especially for warm stratocumulus found over the tropical oceans (e.g., Stevens, 2002; Mellado, 2017). In particular, representing the buoyancy flux and the subsequent top-down convection associated with cloud top radiative cooling and to a lesser extent, with the evaporation or sublimation of condensates (see for instance large eddy simulation studies in Brient, Couvreux, Villefranque, Rio, \& Honnert, 2019), requires specific parameterizations (Lenderink \& Holtslag, 2000).

Some studies using 1-order turbulent mixing schemes proposed to adapt the vertical profiles of the eddy-diffusivity coefficient between the ground and the cloudy boundarylayer top depending on the radiative and evaporative cooling (Lock et al., 2000; Wilson, 2015; Ghonima et al., 2017). However, such schemes do not properly apply for mid-tropospheric clouds. In this study, we follow the approach of Guo et al. (2019) based on the pioneering ideas of Deardoff (1972), Lock (1998) and Grenier and Bretherton (2001). This study includes a specific parameterization for the TKE production term associated with the buoyancy flux at the top of a liquid cloud. Briefly, this parameterization accounts for the buoyancy flux associated with the fraction of the radiative flux divergence that is not explicitly resolved by the model due to its too coarse vertical resolution. This additional TKE production term $P_{R}$ can read:

$$
P_{R}=\mathcal{F}\left(q_{c}, p\right) \frac{g}{\theta_{v}} \frac{\Delta_{z} F_{L W} \Delta z}{c_{p} \rho \Pi}
$$


where $g$ is the acceleration of gravity, $\theta_{v}$ is the virtual potential temperature, $\rho$ is the air density, $c_{p}$ is the air heat capacity, $\Pi$ is the Exner function, $\Delta z F_{L W}$ is the longwave radiative flux vertical divergence at cloud top and $\Delta z$ is the cloud top model layer depth. $\mathcal{F}\left(q_{c}, p\right)$ is a function of the cloud liquid water content $q_{c}$ and pressure $p$ and is bounded between 0 and 1 . Because estimating $\mathcal{F}$ for a mixed-phase cloud would be much more complex, we decide to follow a simplified approach:

$$
P_{R}=\phi \frac{g}{\theta_{v}} \frac{\Delta_{z} F_{L W} \Delta z}{c_{p} \rho \Pi}
$$

with $\phi$ is tuning coefficient ranging between 0 and 1. By default, we set $\phi=0.05$ (value that gives reasonable cloud top liquid content and turbulence, see next section) but the sensitivity to this value will be assessed.

\section{Results}

\subsection{Brief description of the evolution of clouds and precipitation from observations}

The synoptic conditions at 00 UTC, 15 February 2018 in the ctrl WRF simulation are plotted in Figure 1. A synoptic weather system manifesting as a minimum of 500hPa geopotential height sets at the north-west of Mawson, advecting warm and moist oceanic air towards the ice sheet along its eastern flank. In particular, a zonally elongated tongue of integrated condensed water content (shading) is moving towards the station and the ship (blue dot). This tongue preceding a warm sector (temperature in cyan contours) corresponds to the warm front of the system. During the 15 and 16 February, the warm front moves to the south-east of the station and dissipates. The ship thus enters the warm sector while the cold front remains far from the coast over the Southern Ocean. Meanwhile, the extra-tropical cyclone progressively weakens at the west of Mawson and disappears during the second half of the 16 February.

Figure 2 shows the time-height plot of the MWACR reflectivity (panel a), Doppler velocity (panel b) and Doppler spectral width (panel c) above the ship during the event. Note that the radar ceased functioning between 13 and 17 UTC, 15 February. In panel a, black contours indicate regions identified as SLW cloud layers using the MPL data. Panel a indicates a pre-precipitation virga period (16 UTC, 14 February to 02 UTC, 15 February) during the arrival of the warm front above the ship and is characterized by 
significant reflectivity values in altitude but not at the surface. This period is followed by actual surface precipitation within the warm sector - with high reflectivity values at the first radar gate - which is followed by a post-precipitation phase (06 to 17 UTC, 16 February) when the extra-tropical cyclone dissipates. Such temporal structure (pre-precipitation virga, surface precipitation, post-precipitation virga) associated with the passage of a warm front above the station was shown to be representative of the precipitation events affecting the coast of Adélie Land (Jullien et al., 2020), East Antarctica. From the lidar data, clear SLW layers are particularly identified:

1. at the top of boundary-layer stratocumulus upstream of the warm front in the cool sector, within the first $1500 \mathrm{~m}$ a.s.l. and between 15 and 22 UTC, 14 February;

2. at the top of the first high frontal clouds (altocumulus), just above pre-precipitation iced-virga between 17 and 21 UTC, 14 February;

3. at the end of the event, sitting on top of post-precipitation ice virga between 11 and 13 UTC, 16 February;

The Doppler velocity field shows that where SLW is present, weakly-negative or even positive values of the mean vertical velocity are measured (see Figure $2 \mathrm{~b}$ and the Doppler velocity distribution conditioned to SLW patches in Figure S1b). Below SLW layers, one can point out rapid alternations of strongly and weakly negative Doppler velocities. Similarly, the Doppler spectral width - that strongly depends on turbulence - exhibits large values within and in the few hundred meters below SLW layers (Figure 2c). The creation and resilience of SLW at the top of the frontal mixed-phase clouds thus appears related to the dynamics of cloud-top convective cells (A. V. Korolev \& Mazin, 2003; A. Korolev et al., 2017) as within mid-latitude altocumulus (Heymsfield et al., 1991; Smith et al., 2009; P. A. Barrett et al., 2020). It is important to note that the lidar signal may be totally attenuated by precipitation, so there could have been SLW between 15 February 02 UTC and 16 February 06 UTC. As a matter of fact, the highest LWP values estimated from the microwave radiometer were measured between 09 and 19 UTC 15 February (see next section). This suggests the presence of SLW layers or patches within or at the top of the deep nimbostratus during this period, especially within or at the summit of layers with both high values of Doppler velocity and Doppler spectral width. The visual inspection of Doppler spectra indeed confirms the occurrence of elevated SLW layers during the precipitation period (Figure S4). 

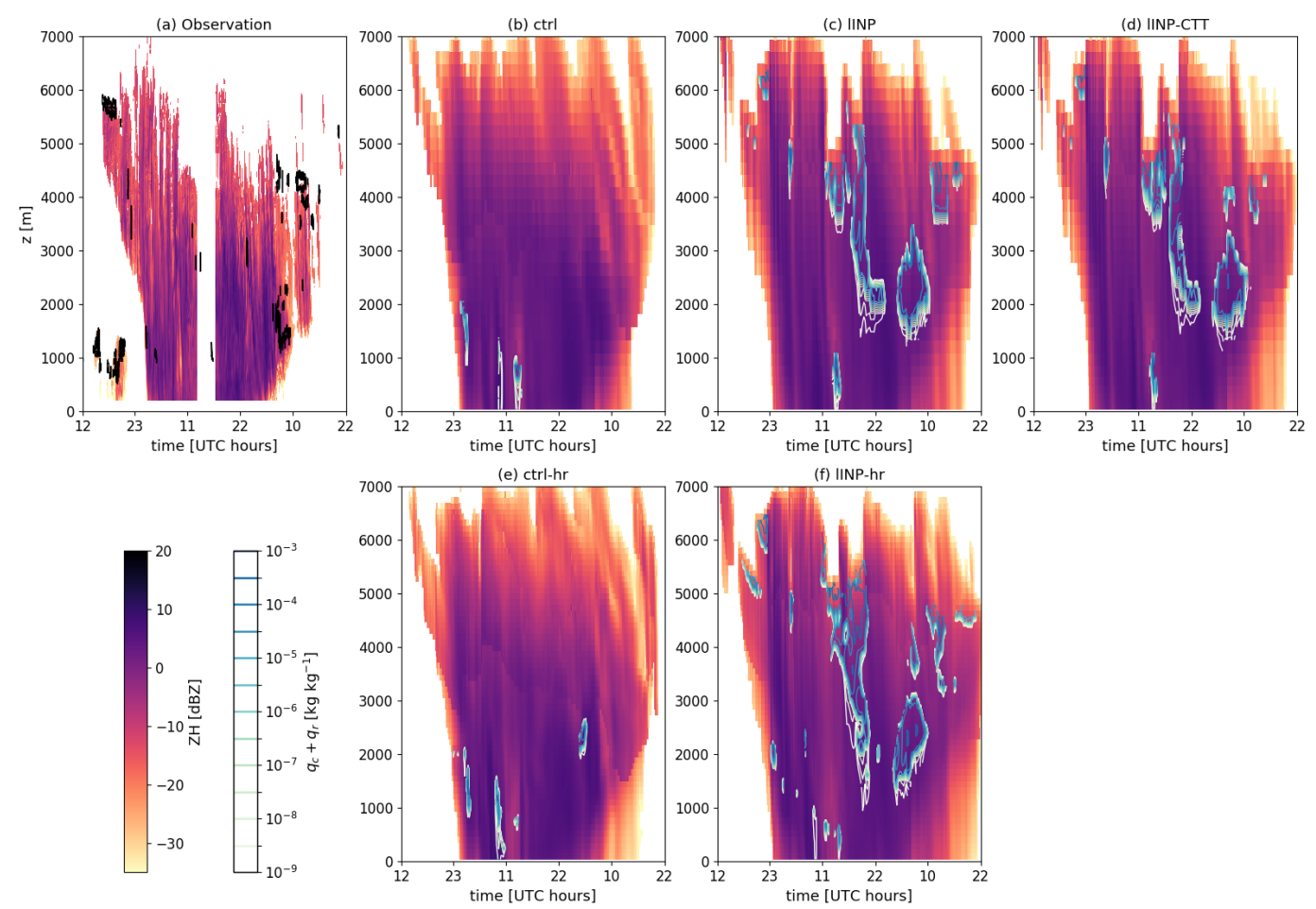

Figure 4. Time-height plot of the W-band reflectivity in MWACR observation (panel a) and as calculated from WRF simulations with the CR-SIM radar simulator (panels b-f). In panel a, black outlines locate regions where the MPL detects SLW. In panels b-f, yellow-to-blue contours show the mass mixing ratio of cloud liquid water (sum of cloud and rain droplets).

\subsection{Simulating the vertical structure of liquid-topped frontal mixed-phase clouds}

We now assess the ability of WRF to reproduce the observed cloud vertical structure. Unlike the control (ctrl) simulation with the standard Morrison microphysical scheme, simulations using the empirical high-latitude Southern Ocean ice nucleation parameterization with a lower - but more realistic - INP concentration, are named 'IINP'. Simulations accounting for the cloud top turbulence parameterization are named with the "CTT' suffix. Likewise, simulations run with the refined vertical grid in the troposphere are designated with the '-hr' suffix.

Figure 4 shows that the ctrl simulation reproduces the timing and the overall structure of the system reasonably well. However the local low-level clouds preceding the passage of the warm front are absent in the simulation above the ship position but similar 
local clouds form a few kilometers away (not shown). In addition, the model generally overestimates the cloud top height particularly owing to the excessive ice nucleation at cold temperatures. More importantly, Figures $4 \mathrm{~b}$ and $5 \mathrm{~m}$ show that the ctrl configuration produces almost fully glaciated clouds and refining the vertical grid in the mid-troposphere (ctrl-hr simulation) barely improves the production of liquid droplets. Note that changing the microphysical scheme to the one from Thompson et al. (2008) - that together with the Morrison scheme yields the best cloud liquid water content and surface radiative fluxes in previous Antarctic studies with WRF (Listowski \& Lachlan-Cope, 2017; Hines et al., 2019) - leads to the same conclusion (not shown). Note also that replacing the INP formulation with the one from DeMott et al. (2010) in the deposition/condensation freezing nucleation parameterization leads to slightly more SLW in the lowest part of the clouds (where the temperature is greater than $-15^{\circ} \mathrm{C}$ ) but its overall amount remains strongly underestimated. It is also worth mentioning that unlike WRF in its standard configuration, the recent ERA5 reanalysis produces some cloud liquid content during this event, but not the correct amount nor at the correct location (at too low altitude and too warm temperature, see Sect. 3 of the supporting information).

The empirical INP formulation leads to a significant increase in cloud liquid water content throughout the event (Figures $4 \mathrm{c}$ and $5 \mathrm{~m}$ ). In addition, the IINP simulation exhibits sharp vertical gradients of condensate mixing ratio in the uppermost part of the clouds. Subsequently, the cloud top radiative cooling is stronger and the resulting buoyancy flux triggers and enhances significant turbulence that is absent in the ctrl simulation (Figure 6).

Panels a-f and g-l of Figure 5 show vertical profiles of atmospheric variables for two particular times with clear liquid-topped altocumulus identified in observations (see vertical green lines in Figure 1a-c). During the arrival of the warm front at 1730 UTC, 14 February 2018, the new INP parameterization makes WRF able to reach the saturation with respect to liquid in a layer around $5600 \mathrm{~m}$ whatever the vertical resolution employed. A thin SLW layer is therefore simulated at cloud top but its height is slightly underestimated compared to lidar observations. Below this layer, ice crystals grow by vapor deposition and sediment (Figure 7). The presence of liquid droplets at cloud top also enhances the radiative cooling, leading to an almost neutral vertical profile of potential temperature in agreement with radiosonde observation (Figure 5a). However, with the coarse vertical resolution employed in lINP, the liquid layer does not persist in time. When re- 
fining the vertical resolution (IINP-hr simulation), the resilience of the SLW layer during the warm front arrival (Figure 4f) is better reproduced - in agreement with the 1Dsimulations of A. I. Barrett et al. (2017b). The altitude of the liquid layer gradually decreases owing to the drying effect associated with cloud-top turbulent entrainment.

The IINP simulation does not reproduce the cloud top turbulence during this specific period (Figure 5f) but lINP-hr exhibits both a resilient SLW layer and vigorous mixing. Activating the additional parameterization for cloud top turbulence enhancement in the low-resolution configuration (IINP-CTT simulation) helps generate turbulence in the upper part of the altocumulus. A similar conclusion can be drawn for the middle phase of the event (around 1200 UTC, 15 February, see Figure 6d). However, this parameterization does not improve the persistence of the SLW layer through time. Turbulence tends to thin the SLW layer out by mixing it with underlying and overlying drier air. As expected, increasing the $\phi$ parameter increases the TKE and $\epsilon$ but for $\phi \geq 0.1$, the mixing becomes too intense - with respect to the vertical resolution used - for SLW to survive over more than a few time steps (see Figure S6).

Similarly to the IINP-CTT simulation, the turbulence in the IINP-hr simulation tends to thin the SLW layer by mixing with drier air (Figure 5d). Interestingly, SLW does not form in the atmospheric layer where turbulent mixing cools the air (Figure 7). This is somewhat contradictory with the conceptual model of supercooled droplet condensation within adiabatically cooled turbulent updrafts (P. A. Barrett et al., 2020). This aspect will be discussed in Sect. 4.3.

Analysis of profiles at 1230 UTC, 16 February (Figure 5g-l) generally concurs with our main inferences regarding the performances of WRF at the beginning of the event. We can still notice the absence of turbulence between 3000 and $4600 \mathrm{~m}$ in the IINP-hr simulation which is explained by the cloud being too deep (see Figure $4 \mathrm{f}$ and Figure $5 \mathrm{~h}$ ) - so an overestimated cloud top height and underestimated radiative cooling between 4000 and $4500 \mathrm{~m}$ (Figure 3k) - at this specific time. We do not have a clear explanation for this bias but it seems that the deep nimbostratus stays too long over the ship location and, interestingly, a thin SLW layer at around $4600 \mathrm{~m}$ is simulated during the end of the 16 February (Figure 4f). In absence of turbulence, the SLW layer in the IINP and IINPhr simulations - at this specific time - is too thick. It becomes more realistic later in the day (see Figure 4). 

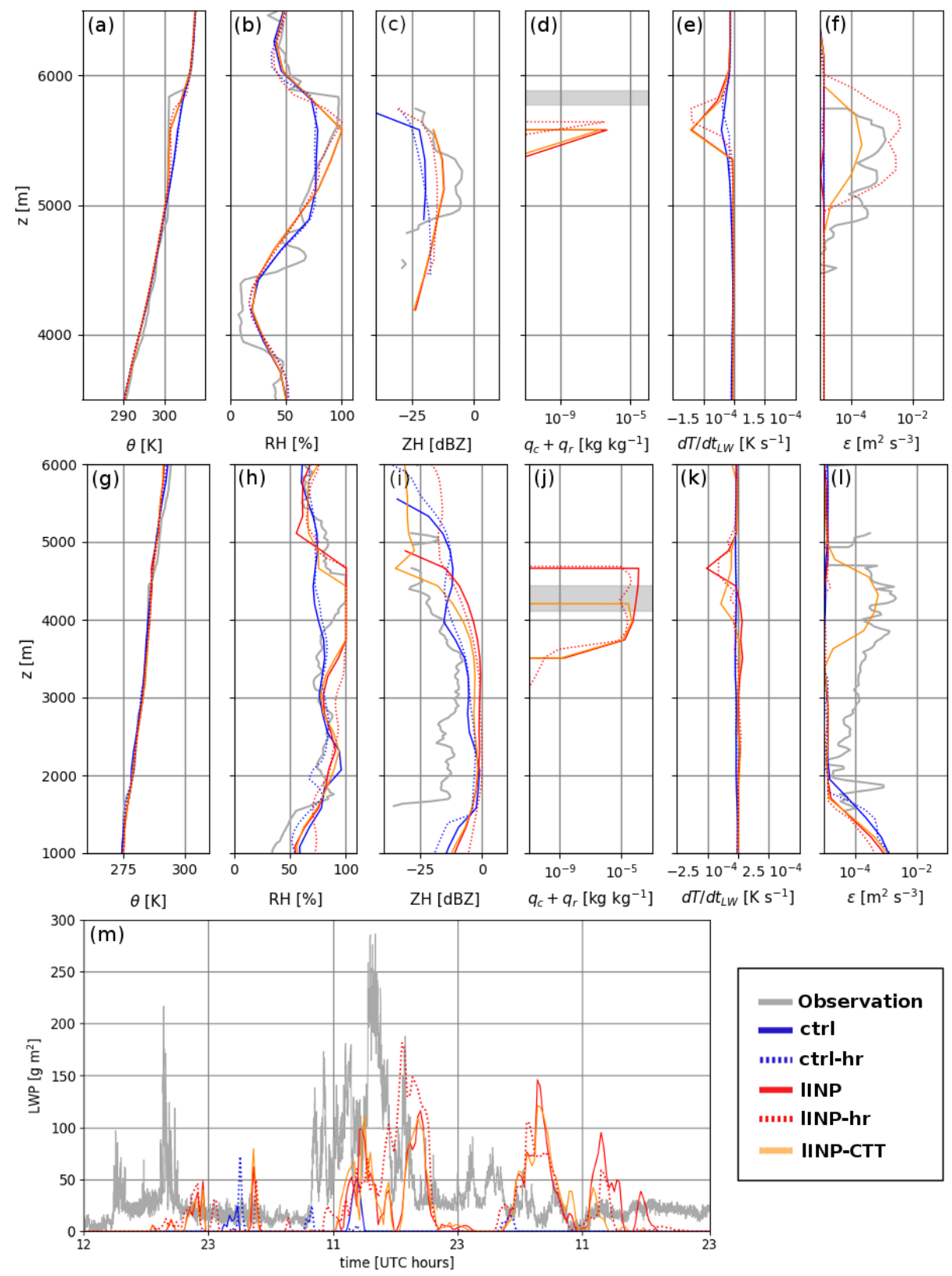

Figure 5. Panels a-l: Vertical profiles of the potential temperature (a and g), relative humidity with respect to liquid (b and h), W-band radar reflectivity (c and i), liquid water content (sum of cloud droplets and rain drops, $\mathrm{d}$ and $\mathrm{j}$ ), temperature tendency due to longwave radiative warming (e and k) and rate of turbulent kinetic energy dissipation (f and l) in observations (grey lines) and WRF simulations. Panels a-f refers to the 14 February 2018 at 1730 UTC while panels g-l refers to the 16 February 2018 at 1230 UTC. In panels a, b, g and h, observational data are from the closest-in-time radiosounding. In panels c, f, i and l, observations are from MWACR data. In panels $\mathrm{d}$ and $\mathrm{j}$, the grey shading indicates the altitude range where the MPL detects SLW. Panel m: 14-16 February 2018 LWP time series above the Aurora Australis position from radiometer estimations (grey line) and from WRF simulations. 

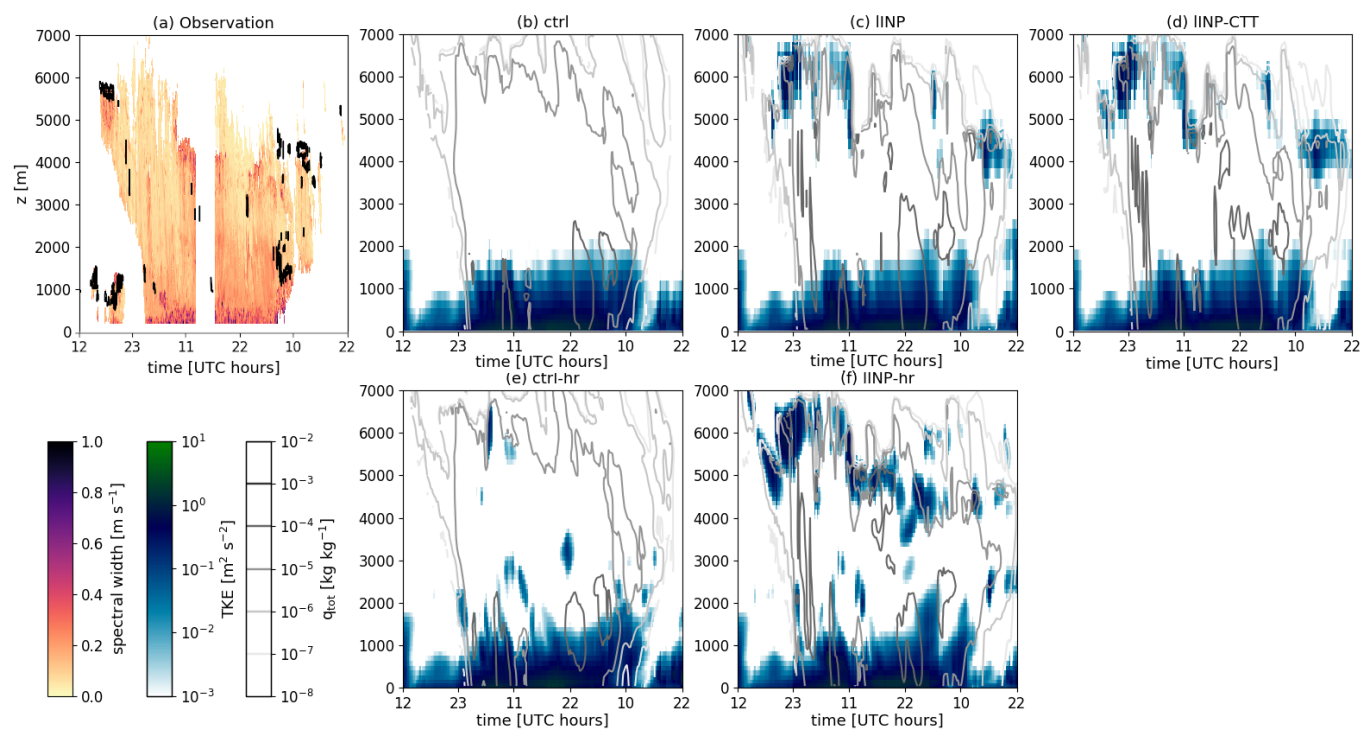

Figure 6. Panel a: Time-height plot of the spectral width in MWACR observation. Black outlines locate regions where the MPL detects SLW. Panels b-f: Time height plots of the TKE (color shading) and of the mass mixing ratio of cloud condensates (contours, sum of cloud droplet, cloud ice, snow, graupel and rain species, $\mathrm{q}_{\text {tot }}$ ) above the ship position for different WRF simulations.

As previously mentioned, Sotiropoulou et al. (2020) suggest that secondary ice production through ice particle collisional break-up might be an important process in coastal Antarctic clouds. We have assessed the model sensitivity to this process on our study case (details in Sect. 4 of the supporting information). Collisional break-up significantly modifies the ice particle number concentration at temperature greater than $-25^{\circ} \mathrm{C}$ but the available observational dataset does not enable us to state whether this is truly beneficial to our simulations or not. In any case, this parameterization is not detrimental to the simulation of SLW layers which is our main scope here.

\subsection{Cloud radiative effect}

Achieving the simulation of SLW layers substantially impacts the cloud radiative effect (CRE) during the event. Figure 8 shows the difference in CRE averaged over the whole study case between the IINP-hr (the configuration with the most realistic SLW layers) and ctrl simulations. At the top of the atmosphere (TOA), the lINP-hr simulation exhibits more reflected shortwave radiation than the ctrl simulation (panel a), es- 


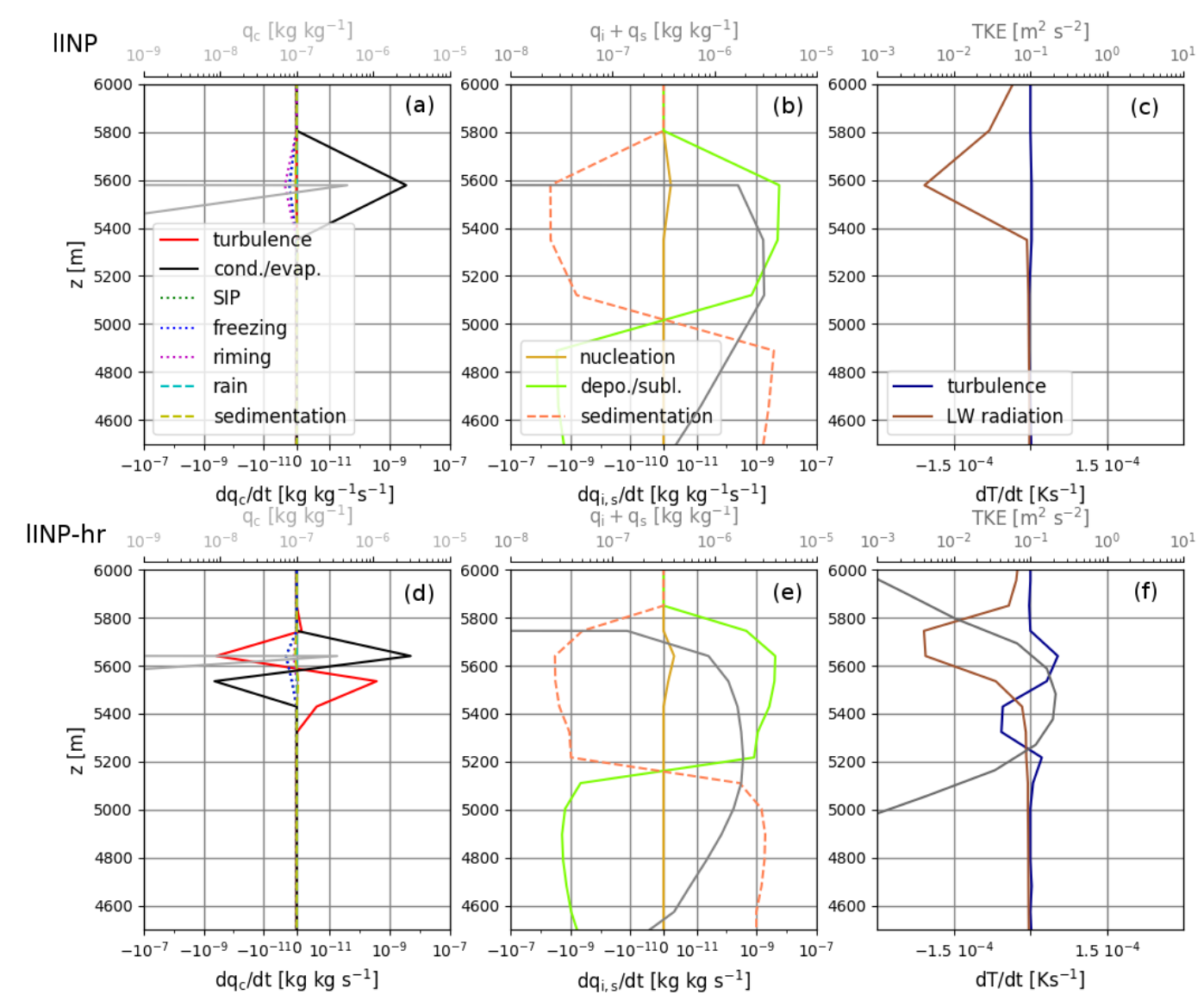

Figure 7. Vertical profiles at 1730 UTC, 14 February 2018, of different model variables for the IINP (panels a-c) and IINP-hr (panels d-f) WRF simulations. Panels a and d show the cloud liquid water content ( $\mathrm{q}_{\mathrm{c}}$, light grey line, top $\mathrm{x}$-axis) and the different source/loss terms of cloud liquid water (colored lines, note the logarithmic scale on x-axis). 'turbulence' refers to turbulent mixing; 'cond./evap.' refers to droplet condensation or evaporation in a saturated/unsaturated atmosphere; 'SIP' refers to secondary ice production by splintering of droplets accreted on iced hydrometeors; 'riming' refers to the riming of iced precipitation; 'freezing' refers to the icenucleation through freezing (loss term for droplets), 'rain' refers to the autoconversion to rain and 'sedimentation' refers to the sedimentation of droplets. Panels b and e show the mass mixing ratio of the ice and snow specied $\left(\mathrm{q}_{i}+\mathrm{q}_{\mathrm{s}}\right.$,grey line, top $\mathrm{x}$-axis $)$ and the relative tendencies due to ice nucleation (solid gold line), vapor deposition or sublimation (solid green line) and sedimentation (dashed orange line). Panels c and f: TKE (dark grey line, top $\mathrm{x}$-axis), longwave radiative (brown) and turbulent (blue) heating rates. Note that the model does not simulate any TKE in panel c. 
pecially over the Southern Ocean because of an increase in cloud albedo, while the albedo discrepancy over snow and ice covered areas over the continent is less significant. This increase in albedo is also responsible for a decrease in the amount of shortwave radiation that reaches the ground surface (Figure 8d). On the other hand, the outgoing longwave radiative flux towards space diminishes due to colder cloud tops. Importantly, as liquid-bearing clouds are optically thicker, the IINP-hr simulation shows a much higher downward radiative flux, leading to a significant surface warming over the ice sheet surface with respect to the ctrl simulation (panel f). The same conclusions can be drawn for the IINP and IINP-CTT simulations. It is also worth noting that although our new parameterizations targeted mid-level clouds, inspection of vertical profiles of cloud properties over the whole simulation domain shows that boundary-layer clouds are also - but to a lesser extent because of the warmer temperatures at lower altitude - modified with higher SLW content. Figure 8 thus integrates combined effects from changes on both midlevel and low-level clouds. Comparison of the surface downward longwave radiative flux above the ship also reveals a better agreement when the new INP parameterization is activated. The mean downwelling longwave flux value between 1200 UTC, 14 February and 2200 UTC, 16 February equals $292.2 \mathrm{~W} \mathrm{~m}^{-2}$ in the observations, and $227.5 \mathrm{~W} \mathrm{~m}^{-2}$, $237.6 \mathrm{~W} \mathrm{~m}^{-2}, 238.0 \mathrm{~W} \mathrm{~m}^{-2}, 241.1 \mathrm{~W} \mathrm{~m}^{-2}$ in the ctrl, IINP, IINP-CTT and IINP-hr simulations respectively. The value is however significantly underestimated in all the simulations. Inspection of flux time series (not shown) reveals that this is mostly due to the absence of local low-level clouds just above the ship position and preceding the warm front. Such clouds indeed have a particularly strong warming effect. Comparison with model grid points in the vicinity of the ship that contains low-level clouds shows a substantially higher (up to $40 \mathrm{~W} \mathrm{~m}^{-2}$ ) downward longwave radiative flux at the arrival of the warm front.

\section{Discussion}

\subsection{Remaining shortcomings in our simulations}

Despite improvements regarding the simulation of SLW layers, shortcomings remain in our simulations whatever the physical configuration used. Amongst the most striking biases, Figures 4 and $5 \mathrm{~h}$ evidence an insufficient low-level sublimation during the last day of the event that is associated with an overestimation of the relative humidity when comparing with radiosoundings. This aspect can be improved when accounting for sec- 
(a) diff. CRE SW TOA
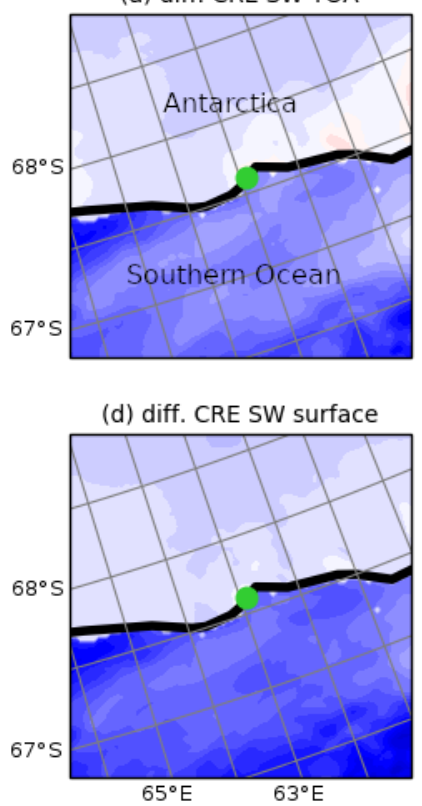

(b) diff. CRE LW TOA

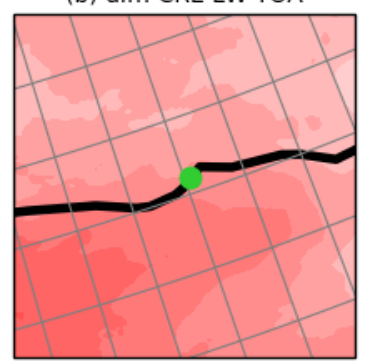

(e) diff. CRE LW surface

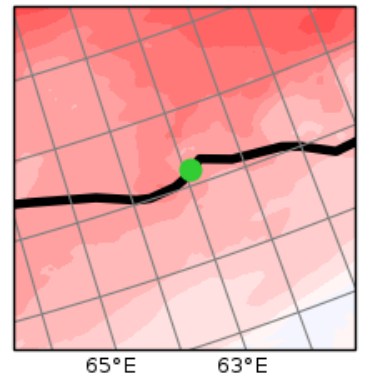

(c) diff. CRE TOA

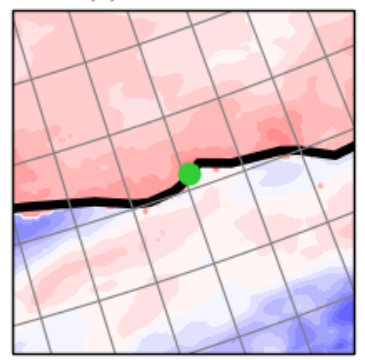

70

35

2
1
3

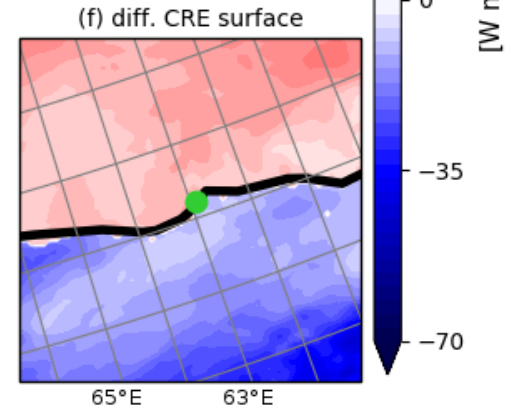

Figure 8. Difference in cloud radiative effect (CRE) averaged over the whole duration of the study case at the top of the atmosphere (TOA, top row) and at the surface (bottom row) between the IINP-CTT and ctrl WRF simulations (3-km resolution innermost domain). Panels a and d show the shortwave (SW) component, panels b and e the longwave (LW) component, and panels $\mathrm{c}$ and $\mathrm{f}$ the total difference. The black line is the Antarctic landfall and the green dot locates Mawson station. 
ondary ice production through ice particle break-up (see Sect. 4 of the supporting information).

Figure $5 \mathrm{~m}$ also reveals an overall underestimation of the LWP in all the simulations as well as issues concerning the timing of the LWP peaks. Changing the intensity of the 27-km domain nudging or adding a nudging term on the temperature and/or the humidity fields did not alleviate those biases (not shown). A bias propagation from the ERA5 forcings into our inner simulation domains can thus not be excluded. Moreover, the absence of lidar measurements during the strong precipitation phase that coincides with the highest LWP values prevents us from precisely evaluating the SLW representation during this period. Warm frontal systems often exhibit SLW layers or patches within deep nimbostratus associated with embedded convective cells (Keppas et al., 2018). The MWACR data shows high values (in magnitude) of the Doppler velocity and of the Doppler spectral width at the top of the nimbostratus between 9 and 13 UTC, 15 February, suggesting that intense cloud-top turbulent updrafts may explain a significant part of the SLW production during this period. In addition to turbulence, Gehring et al. (2020) show that within a nimbostratus over Korea, the large scale ascent corresponding to the warm conveyor belt of an extra-tropical cyclone can be sufficient to create and sustain SLW. Comparing Figure 4 and Figure 6 shows that the IINP and IINP-hr simulations also exhibit SLW patches in the middle of the nimbostratus (between about 2000 and $3500 \mathrm{~m}$ ) i.e. in an altitude range with low values of TKE in the model and low values of spectral width in the MWACR data. Further inspection of the resolved vertical velocity field in the model reveals that those SLW patches coincide with significant ascents (around $+0.1-0.2 \mathrm{~m} \mathrm{~s}^{-1}$, not shown) but their realism cannot be assessed by comparison with our observational dataset. Hence, it remains difficult to disentangle whether the remaining biases in SLW quantity and timing during the precipitation period are due to a poor representation of the turbulence at the top of the nimbostratus and/or to the modeling of the large-scale ascent associated with synoptic dynamics.

\subsection{INP, turbulence, vertical resolution: what matters the most for achiev- ing the simulation of SLW layers?}

Our results highlight that without a realistic ice nucleation parameterization that accounts for the particularly low INP concentration over the high-latitude Southern Ocean, the representation of thin turbulent SLW layers and realistic SLW contents cannot be 
achieved. This conclusion holds whatever the vertical resolution tested, with or without additional subgrid turbulent mixing at cloud top. From the present analysis, the nature of the heterogeneous ice nucleation parameterization in atmospheric models, especially the representation of the limited INP numbers concentrations over this region, is an essential prerequisite to simulate the liquid phase in frontal mid-level mixed-phase clouds at high southern latitudes. Furthermore, it makes the model produce significant TKE near cloud top - which is missing in the ctrl simulation - due to enhanced radiative divergence. In our IINP and IINP-hr simulations, the persistence of the saturation with respect to liquid - and of the resulting SLW layer - mostly depends on a subtle competition between air cooling (primarily due to radiative divergence, see Figure 7) and moisture removal associated with the growth of ice crystals. Increasing the vertical resolution usually helps maintain the saturation because newly formed crystals get more easily separated from the liquid layer while falling. One can refer to A. I. Barrett et al. (2017b) for further discussion on the link between SLW resilience and model vertical resolution. In IINP, although SLW continues to form at 1730 UTC, the ice particle growth (Figure 7) makes the air under-saturated with respect to liquid after a few minutes. When the liquid layer disappears, the precipitating ice crystals falling towards the lower layer are not replaced by newly formed crystals and the total cloud water content decreases. The reappearance of SLW becomes impossible if other moistening processes (through advection for instance) do not come into play or until the temperature reaches the dew point through radiative cooling. In contrast in IINP-hr, the atmospheric layer between 5600 and $5750 \mathrm{~m}$ shows lower ice crystal concentration, a weaker vapor deposition on ice and significant radiative cooling (Figure 7), enabling the persistence of the SLW layer for several hours.

Regarding the representation of turbulence, the underestimation of the occurrence and intensity of cloud top mixing at coarse vertical resolution could be anticipated and motivated the implementation of an additional source term in the TKE equation. The latter parameterization leads to better agreement with $\epsilon$ estimations from Doppler radar measurements during the front arrival and during the course of the event. However and unlike the increase in vertical resolution, this parameterization does not help sustain the SLW layer and conversely it can amplify its depletion if the $\phi$ coefficient is set to a too high value. This apparent second role of turbulence for SLW resilience may be co-incidental since the state-of-the-art MYNN local turbulent mixing scheme is likely inadequate for 
reproducing the top-down convection at mid-level cloud top. This may even question the physical representation of cloud droplet formation and growth in the model (see next section).

\subsection{The pressing need of revisiting the parameterization of cloud top turbulence}

One aspect that particularly deserves further discussion is the representation of cloud top turbulence in the model. We have shown that in some cases, an additional source term in the TKE equation, compensating for the incomplete reproduction of the radiative cooling, helps obtain some TKE at cloud top. However the local TKE generation by buoyancy fluxes in the IINP-CTT and IINP-hr (and to a lesser extent in the IINP) simulations lead to a patch of TKE (or $\epsilon$ ) that is vertically centered around cloud top liquid and that unrealistically diminishes the temperature inversion (Figure 5a,f and 7f). Even though our estimation of $\epsilon$ only applies where the radar detects signal in the cloud, the sharp temperature inversion in the observations suggests that turbulent motions mostly occur within and below the cloud. Using turbulence data from aircraft measurements, P. A. Barrett et al. (2020) show that the TKE maximum occurs several hundred meters below typical mixed-phase altocumulus top. Indeed, the turbulence structure within altocumulus consists of shallow small-scale eddies at cloud top below which an organized Rayleigh Bénard-type convection takes place with negatively buoyant air parcels that descend through the cloud layer in coherent downdrafts and force upward motion through mass continuity (Schmidt et al., 2014; P. A. Barrett et al., 2020). Subrotor circulations associated with ice virga shafts may also participate in the mixing below the cloud. Overall the organized convection triggered at cloud-top cannot be represented by the typical local turbulent mixing schemes used in atmospheric models like MYNN or all the current 1.5-order planetary boundary layer schemes in WRF. Moreover, the adiabatic cooling, the saturation with respect to liquid and the growth and vertical transport of droplets only occurs within updrafts. Considering each model layer as homogeneous in terms of temperature and humidity necessarily prevents the proper representation of the dynamics of turbulent mixed-phase clouds. Albeit satisfactory compared to simulations with the standard version of WRF, the representation of SLW layers in the IINP-hr configuration may result from a partially non-physical interplay between turbulence and microphysics. Adapting a non-local turbulent mixing parameterization based on a mass- 
flux scheme that treats separately a 'lifting' fraction and a 'subsiding' fraction of each mesh (see Hourdin et al., 2019 for instance) might be an interesting approach to tackle this issue in the future. Such types of scheme are already active in many atmospheric models to parameterize the mixing in convective ground-based boundary layers but they are not active aloft.

\section{Conclusions}

By using remotely-sensed measurements obtained during the MARCUS campaign, we have evaluated the ability of the WRF regional atmospheric model to reproduce the thin and turbulent layers of SLW at the top of frontal mixed-phase clouds over the highlatitude Southern Ocean.

While the control simulation did not exhibit any cloud liquid water above the boundary layer, we found that modifying the ice nucleation parameterization through the implementation of a truly representative INP concentrations measured around the time of the event considerably improved our simulation results. We can thus infer that adapting the ice nucleation parameterization to the particularly pristine conditions prevailing over the Southern Ocean is essential for atmospheric models running over this region, in agreement with the conclusions of Vergara-Temprado et al. (2018). Refining the vertical resolution in the troposphere led to slightly higher liquid water content, but, first and foremost, it allowed us to simulate more stable-in-time SLW layers and to simulate vigorous and frequent turbulence within clouds. At coarse vertical resolution, the enhanced cloud-top radiative cooling associated with the cloud droplet production still made it possible to simulate some turbulence in mid-level clouds. An additional parameterization for cloud-top turbulence generation further led to more realistic comparison with radar estimations of the TKE dissipation rate during specific periods like during the arrival of the warm front, but it does not help sustain the SLW layer at altocumulus top.

Our changes in the model physics considerably modified the simulated CRE during the event. Amongst the most prominent signals, we could point out a pronounced decrease in CRE at the ocean surface due to more shortwave radiation reflected toward space by the more realistic SLW layers and an increase in CRE at the ice sheet surface owing to an enhanced downward longwave radiative flux. Despite improvements regarding the simulation of SLW, the timing and the correct quantity of the LWP were still not 
satisfactorily reproduced, questioning the representation of cloud-top liquid layers and/or embedded liquid patches within clouds during the precipitation period.

Albeit very promising, our new ice nucleation parameterization based on an INP concentration formulation that only depends on temperature cannot be fully satisfactory since it does not account for the true link between aerosol populations and ice nucleation. This calls for a future more accurate aerosol-aware formulation for INPs in the high-latitude Southern Ocean.

Importantly, the way turbulent mixing at cloud top is represented - and hence the physical representation of liquid droplet condensation and growth in mixed-phase clouds - remains questionable since the local 1.5 order turbulent mixing parameterization does not properly account for non-local convective transport and since it does not treat separately the respective evolution of rising and subsiding air parcels. This invites further parameterization development targeting the top-down convection at cloud-top, taking, for instance, inspiration from mass-flux schemes used to treat the mixing by thermal plumes in convective boundary-layers.

Last but not least, our work does not enable us to draw any robust conclusions about the ability of WRF to reproduce the low-level mixed-phase clouds which have strong radiative effects at the surface in our study case and which explain the major part of the radiative bias over the Southern Ocean in CMIP models. Future studies are thus needed to broach this aspect, tackling in particular the coupling - or decoupling - between clouds and the ocean surface, the effect of surface evaporation and the interactions with the boundarylayer dynamics.

\section{Acknowledgments}

This work was funded by the EPFL-LOSUMEA project. The contribution of S.A. was supported through Australia Antarctic Science projects 4292 and 4387 and we thank Steven Whiteside, Lloyd Symonds, Rick van den Enden, Peter de Vries, Chris Young and Chris Richards for assistance. P.D. acknowledges support from the U.S. Department of Energy's (DOE) Atmospheric System Research, an Office of Science Biological and Environmental Research program, under Grant No. DE-SC0018929, and use of data obtained from the DOE Atmospheric Radiation Measurement (ARM) User Facility. We thank Constantino Listowski, Jean-Baptiste Madeleine, Noémie Planat, Michael Lehning and Varun 
Sharma for fruitful discussions, Josué Gehring for his help for the turbulence dissipation rate estimations from radar data and Jay Mace for helping calibrate the radar measurements. We also gratefully thank Kevin Barry for assisting with processing of the INP samples. Technical, logistical and ship support for MARCUS were provided by the AAD through Australian Antarctic Science projects 4292 and 4387. MARCUS data are freely available from the ARM data archive (https://www.arm.gov/data) and MARCUS experiment webpage (https://www.arm.gov/research/campaigns/amf2017marcus). ERA5 reanalyses can be freely downloaded from the Copernicus climate data store (https:// cds.climate.copernicus.eu). The original WRF code is open source. The new WRF topography file from the Reference Elevation Model of Antarctica dataset will be made freely available if the paper is accepted.

\section{References}

Alexander, S. P., \& Protat, A. (2018). Cloud properties observed from the surface and by satellite at the northern edge of the southern ocean.

Journal of Geophysical Research: Atmospheres, 123(1), 443-456. ～doi: 10.1002/ 2017JD026552

Andronache, C., \& coauthors. (2017). Mixed phase clouds : observations and modeling. elsevier edition. doi: 10.106/B978-0-12-810549-8.00007-6

Barrett, A. I., Hogan, R. J., \& Forbes, R. M. (2017a). Why are mixed-phase altocumulus clouds poorly predicted by large-scale models? part 1 . physical processes. Journal of Geophysical Research: Atmospheres, 122(18), 9903-9926. doi: 10.1002/2016JD026321

Barrett, A. I., Hogan, R. J., \& Forbes, R. M. (2017b). Why are mixed-phase altocumulus clouds poorly predicted by large-scale models? part 1 . vertical resolution sensitivity and parameterization. Journal of Geophysical Research: Atmospheres, 122(18), 9922-9944. doi: 10.1002/2016JD026322

Barrett, P. A., Blyth, A., Brown, P. R. A., \& Abel, S. J. (2020). The structure of turbulence and mixed-phase cloud microphysics in a highly supercooled altocumulus cloud. Atmospheric Chemistry and Physics, 20(4), 1921-1939. Retrieved from https://www.atmos-chem-phys.net/20/1921/2020/ doi: 10.5194/acp-20-1921-2020

Bigg, E. K. (1953). The supercooling of water. Proceedings of the Physical Society. 
Section B, 66(8), 688 .

Bodas-Salcedo, A., Andrews, T., Karmalkar, A. V., \& Ringer, M. A. (2016). Cloud liquid water path and radiative feedbacks over the southern ocean. Geophysical Research Letters, 43(20), 10,938-10,946. doi: 10.1002/2016GL070770

Bodas-Salcedo, A., Williams, K. D., Ringer, M. A., Beau, I., Cole, J. N. S., Dufresne, J.-L., ... Yokohata, T. (2014). Origins of the solar radiation biases over the southern ocean in cfmip2 models. Journal of Climate, 27(1), 41-56. doi: 10.1175/JCLI-D-13-00169.1

Brient, F., Couvreux, F., Villefranque, N., Rio, C., \& Honnert, R. (2019). Objectoriented identification of coherent structures in large eddy simulations: Importance of downdrafts in stratocumulus. Geophysical Research Letters, 46(5), 2854-2864. doi: 10.1029/2018GL081499

Cooper, W. A. (1986). Ice initiation in natural clouds. Meteor Mon, 21, 29-32.

Deardoff, J. W. (1972). On the entrainment rate of a stratocumulus-topped mixed layer. Q J R Meteorol Soc, 102, 503-583.

de Boer, G., Hashino, T., Tripoli, G. J., \& Eloranta, E. W. (2013). A numerical study of aerosol influence on mixed-phase stratiform clouds through modulation of the liquid phase. Atmospheric Chemistry and Physics, 13(4), 17331749. doi: 10.5194/acp-13-1733-2013

DeMott, P. J., Hill, T. C., McCluskey, C. S., Prather, K. A., Collins, D. B., Sullivan, R. C., ... others (2016). Sea spray aerosol as a unique source of ice nucleating particles. $\quad$ Proceedings of the National Academy of Sciences, 113(21), $5797-5803$.

DeMott, P. J., Hill, T. C., \& McFarquhar, G. (2018). Measurements of aerosols, radiation, and clouds over the southern ocean (marcus) ice nucleating particle measurements field campaign report. $\quad E d$. by Robert Stafford, ARM user facility, DOE/SC-ARM-18-031.

DeMott, P. J., Prenni, A. J., Liu, X., Kreidenweis, S. M., Petters, M. D., Twohy, C. H., ,. Rogers, D. (2010). Predicting global atmospheric ice nuclei distributions and their impacts on climate. Proceedings of the National Academy of Sciences, 107(25), 11217-11222.

Flato, G., \& coauthors. (2013). Evaluation of climate models. Climate Change 2013: The Physical Science Basis, T. F. Stockeret al., Eds., Cambridge University 
Press, 741-866.

Forbes, R., \& Ahlgrimm, M. (2014). On the representation of high-latitude boundary layer mixed-phase cloud in the ecmwf global model. Mon Wea Rev, 142, $3425-3445$.

Furtado, K., Field, P. R., Boutle, I. A., Morcrette, C. R., \& Wilkinson, H. (2016). A physically based subgrid parametrization for the production and maintenance of mixed-phase clouds in a general circulation model. J Atmos Sci, 73, 279-291. doi: 10.1175/JAS-D-15-0021.1

Gehring, J., Oertel, A., Vignon, E., Jullien, N., Besic, N., \& Berne, A. Microphysics and dynamics of snowfall associated to a warm conveyor belt over korea. Atmospheric Chemistry and Physics, 2020, 1-35. Retrieved from https://www.atmos-chem-phys-discuss.net/acp-2019-1173/ doi: 10.5194/acp-2019-1173

Gettelman, A., Hannay, C., Bacmeister, J. T., Neale, R. B., Pendergrass, A. G., Danabasoglu, G., ... Mills, M. J. (2019). High climate sensitivity in the community earth system model version 2 (cesm2). Geophysical Research Letters, 46(14), 8329-8337. doi: 10.1029/2019GL083978

Ghonima, M. S., Yang, H., Kim, C. K., Heus, T., \& Kleissl, J. (2017). Evaluation of wrf scm simulations of stratocumulus-topped marine and coastal boundary layers and improvements to turbulence and entrainment parameterizations. Journal of Advances in Modeling Earth Systems, 9(7), 2635-2653. doi: 10.1002/2017MS001092

Gilbert, E., Orr, A., King, J. C., Renfrew, I. A., Lachlan-Cope, T., Field, P. F., \& Boutle, I. A. (2020). Summertime cloud phase strongly influences surface melting on the larsen c ice shelf, antarctica. Quarterly Journal of the Royal Meteorological Society, n/a(n/a). doi: 10.1002/qj.3753

Grazioli, J., Genthon, C., Boudevillain, B., Duran-Alarcon, C., Del Guasta, M., Madeleine, J.-B., \& Berne, A. (2017). Measurements of precipitation in dumont d'urville, adélie land, east antarctica. The Cryosphere, 11(4), 1797-1811. doi: 10.5194/tc-11-1797-2017

Grenier, H., \& Bretherton, C. S. (2001). A moist pbl parameterization for largescale models and its application to subtropical cloud-topped marine boundary layers. Monthly weather review, 129(3), 357-377. 
Guo, Z., Wang, M., Larson, V. E., \& Zhou, T. (2019). A cloud top radiative cooling model coupled with clubb in the community atmosphere model: Description and simulation of low clouds. Journal of Advances in Modeling Earth Systems, 11(4), 979-997. doi: 10.1029/2018MS001505

Hersbach, H., Bell, B., Berrisford, P., Hirahara, S., Horányi, A., Muñoz-Sabater, J., ... Thépaut, J.-N. (2020). The era5 global reanalysis. Quarterly Journal of the Royal Meteorological Society, n/a(n/a). doi: 10.1002/qj.3803

Heymsfield, A. J., Miloshevich, L. M., Slingo, A., Sassen, K., \& Starr, D. O. (1991). An observational and theoretical study of highly supercooled altocumulus. Journal of the atmospheric sciences, 48(7), 923-945.

Hines, K. M., \& Bromwich, D. H. (2008). Development and testing of polar weather research and forecasting (wrf) model. part i: Greenland ice sheet meteorology. Monthly Weather Review, 136(6), 1971-1989. doi: 10.1175/2007MWR2112.1

Hines, K. M., Bromwich, D. H., Wang, S.-H., Silber, I., Verlinde, J., \& Lubin, D. (2019). Microphysics of summer clouds in central west antarctica simulated by polar wrf and amps. Atmospheric Chemistry and Physics Discussions, 2019, 1-48. doi: 10.5194/acp-2018-1251

Hogan, R. J., Francis, P. N., Flentje, H., Illingworth, A. J., Quante, M., \& Pelon, J. (2003). Characteristics of mixed-phase clouds: Part i. lidar, radar and aircraft observations from clare98. Q J R Meteorol Soc, 129, 2089-2116.

Hourdin, F., Jam, A., Rio, C., Couvreux, F., Sandu, I., Lefebvre, M.-P., ... Idelkadi, A. (2019). Unified parameterization of convective boundary layer transport and clouds with the thermal plume model. Journal of Advances in Modeling Earth Systems, 11(9), 2910-2933. doi: 10.1029/2019MS001666

Howat, I. M., Porter, C., Smith, B. E., Noh, M.-J., \& Morin, P. (2019). The reference elevation model of antarctica. The Cryosphere, 13(2), 665-674. doi: 10 $.5194 / \mathrm{tc}-13-665-2019$

Hyder, P., Edwards, J. M., Allan, R. P., Hewitt, H. T., Bracegirdle, T. J., Gregory, J. M., ... others (2018). Critical southern ocean climate model biases traced to atmospheric model cloud errors. Nature communications, 9 .

Jullien, N., Vignon, E., Sprenger, M., Aemisegger, F., \& Berne, A. (2020). Synoptic conditions and atmospheric moisture pathways associated with virga and precipitation over coastal adélie land in antarctica. The Cryosphere, 14(5), 1685- 
1702. Retrieved from https://tc.copernicus.org/articles/14/1685/2020/ doi: $10.5194 /$ tc-14-1685-2020

Kanji, Z. A., Ladino, L. A., Wex, H., Boose, Y., Burkert-Kohn, M., Cziczo, D. J., \& Krämer, M. (2017). Overview of ice nucleating particles. Meteorological Monographs, 58, 1.1-1.33. doi: 10.1175/AMSMONOGRAPHS-D-16-0006.1

Kawai, H., Yukimoto, S., Koshiro, T., Oshima, N., Tanaka, T., Yoshimura, H., \& Nagasawa, R. (2019). Significant improvement of cloud representation in the global climate model mri-esm2. Geoscientific Model Development, 12(7), 2875-2897. doi: 10.5194/gmd-12-2875-2019

Kay, J. E., Wall, C., Yettella, V., Medeiros, B., Hannay, C., Caldwell, P., \& Bitz, C. (2016). Global climate impacts of fixing the southern ocean shortwave radiation bias in the community earth system model (cesm). Journal of Climate, 29(12), 4617-4636. doi: 10.1175/JCLI-D-15-0358.1

Keppas, S. C., Crosier, J., Choularton, T. W., \& Bower, K. N. (2018). Microphysical properties and radar polarimetric features within a warm front. Monthly Weather Review, 146(7), 2003-2022. doi: 10.1175/MWR-D-18-0056.1

King, J. C., Gadian, A., Kirchgaessner, A., Kuipers Munneke, P., Lachlan-Cope, T. A., Orr, A., ... Weeks, M. (2015). Validation of the summertime surface energy budget of larsen c ice shelf (antarctica) as represented in three highresolution atmospheric models. Journal of Geophysical Research: Atmospheres, 120(4), 1335-1347. doi: 10.1002/2014JD022604

Kollias, P., Puigdomènech Treserras, B., \& Protat, A. (2019). Calibration of the 2007-2017 record of atmospheric radiation measurements cloud radar observations using cloudsat. Atmospheric Measurement Techniques, 12(9), 4949-4964. Retrieved from https://www.atmos-meas-tech.net/12/4949/2019/ doi: 10.5194/amt-12-4949-2019

Korolev, A., McFarquhar, G., Field, P. R., Franklin, C., Lawson, P., Wang, Z., ... Wendisch, M. (2017). Mixed-phase clouds: Progress and challenges. Meteorological Monographs, 58, 5.1-5.50. doi: 10.1175/AMSMONOGRAPHS-D-17 $-0001.1$

Korolev, A. V., \& Mazin, I. P. (2003). Supersaturation of water vapor in clouds. Journal of the Atmospheric Sciences, 60(24), 2957-2974. doi: 10.1175/1520-0469(2003)060<2957:SOWVIC $>2.0 . C O ; 2$ 
Lenaerts, J. T. M., Van Tricht, K., Lhermitte, S., \& L'Ecuyer, T. S. (2017). Polar clouds and radiation in satellite observations, reanalyses, and climate models. Geophysical Research Letters, 44(7), 3355-3364. doi: 10.1002/2016GL072242

Lenderink, G., \& Holtslag, A. (2000). Evaluation of the kinetic energy approach for modeling turbulent fluxes in stratocumulus. Monthly weather review, 128(1), $244-258$.

Listowski, C., Delanoë, J., Kirchgaessner, A., Lachlan-Cope, T., \& King, J. (2019). Antarctic clouds, supercooled liquid water and mixed-phase investigated with dardar: geographical and seasonal variations. Atmospheric Chemistry and Physics Discussions, 2019, 1-52. doi: 10.5194/acp-2018-1222

Listowski, C., \& Lachlan-Cope, T. (2017). The microphysics of clouds over the Antarctic peninsula - part 2: modelling aspects within polar wrf. $\quad A t$ mospheric Chemistry and Physics, 17(17), 10195-10221. doi: 10.5194/ acp-17-10195-2017

Lock, A. P. (1998). The parametrization of entrainment in cloudy boundary layers. Q J R Meteorol Soc, 124, 2729-2753.

Lock, A. P., Brown, A. R., Bush, M. R., Martin, G. M., \& Smith, R. N. B. (2000). A new boundary layer mixing scheme. part i: Scheme description and singlecolumn model tests. Monthly Weather Review, 128(9), 3187-3199. doi: 10.1175/1520-0493(2000)128<3187:ANBLMS $\rangle 2.0 . C O ; 2$

Mace, G. G. (2010). Cloud properties and radiative forcing over the maritime storm tracks of the southern ocean and north atlantic derived from a-train. Journal of Geophysical Research: Atmospheres, 115(D10). doi: 10.1029/2009JD012517

Marchand, R., Ackerman, T., Westwater, E. R., Clough, S. A., Cady-Pereira, K., \& Liljegren, J. C. (2003). An assessment of microwave absorption models and retrievals of cloud liquid water using clear-sky data. Journal of Geophysical Research: Atmospheres, 108(D24). doi: 10.1029/2003JD003843

Mason, S., Jakob, C., Protat, A., \& Delanoë, J. ～(2014). Characterizing observed midtopped cloud regimes associated with southern ocean shortwave radiation biases. Journal of Climate, 27(16), 6189-6203. doi: 10.1175/JCLI-D-14-00139.1

McCluskey, C. S., Hill, T. C. J., Humphries, R. S., Rauker, A. M., Moreau, S., 
Strutton, P. G., ... DeMott, P. J. ～(2018). Observations of ice nucleating particles over southern ocean waters. Geophysical Research Letters, 45(21), 11,989-11,997. doi: 10.1029/2018GL079981

Mellado, J. P. (2017). Cloud-top entrainment in stratocumulus clouds. Annual Review of Fluid Mechanics, 49(1), 145-169. doi: 10.1146/annurev-fluid-010816 $-060231$

Meyers, M. P., DeMott, P. J., \& Cotton, W. R. (1992). New primary ice-nucleation parameterizations in an explicit cloud model. Journal of Applied Meteorology, 31 (7), 708-721. doi: 10.1175/1520-0450(1992)031〈0708:NPINPI $\rangle 2.0 . C O ; 2$

Morrison, H., Curry, D. A., \& Khvorostyanov, V. I. (2005). A new double-moment microphysics parametrization for application in cloud and climate models. part i: Description. J Atmos Sci, 62, 1665-1677. doi: 10.1175/jas3446

Morrison, H., De Boer, G., Feingold, G., Harrington, J., Shupe, M. D., \& Sulia, K. (2012). Resilience of persistent arctic mixed-phase clouds. Nature Geoscience, $5(1), 11$.

Nicolas, J. P., Vogelmann, A. M., Scott, R. C., Wilson, A. B., Cadeddu, M. P., Bromwich, D. H., ... others (2017). January 2016 extensive summer melt in west antarctica favoured by strong el niño. Nature communications, 8, 15799 .

O'Shea, S. J., Choularton, T. W., Flynn, M., Bower, K. N., Gallagher, M., Crosier, J., ... Lachlan-Cope, T. (2017). In situ measurements of cloud microphysics and aerosol over coastal antarctica during the mac campaign. Atmospheric Chemistry and Physics, 17(21), 13049-13070. doi: 10.5194/acp-17-13049-2017

Oue, M., Tatarevic, A., Kollias, P., Wang, D., Yu, K., \& Vogelmann, A. M. (2020). The cloud-resolving model radar simulator (cr-sim) version 3.3: description and applications of a virtual observatory. Geoscientific Model Development, 13(4), 1975-1998. doi: 10.5194/gmd-13-1975-2020

Paukert, M., \& Hoose, C. (2014). Modeling immersion freezing with aerosoldependent prognostic ice nuclei in arctic mixed-phase clouds. Journal of Geophysical Research: Atmospheres, 119(14), 9073-9092. Retrieved from https:// agupubs . onlinelibrary .wiley . com/doi/abs/10.1002/2014JD021917 doi: 10.1002/2014JD021917

Protat, A., Schulz, E., Rikus, L., Sun, Z., Xiao, Y., \& Keywood, M. (2017). Ship- 
borne observations of the radiative effect of southern ocean clouds. J Geophys Res Atmos, 121(318328). doi: 10.1002/2016JD026061

Ricaud, P., Del Guasta, M., Bazile, E., Azouz, N., Lupi, A., Durand, P., .. Grigioni, P. (2020). Supercooled liquid water cloud observed, analysed, and modelled at the top of the planetary boundary layer above dome c, antarctica. Atmospheric Chemistry and Physics, 20(7), 4167-4191. Retrieved from https://www.atmos-chem-phys.net/20/4167/2020/ doi: 10.5194/acp-20-4167-2020

Sato, K., Inoue, J., Alexander, S. P., McFarquhar, G., \& Yamazaki, A. (2018). Improved reanalysis and prediction of atmospheric fields over the southern ocean using campaign-based radiosonde observations. Geophysical Research Letters, 45(20), 11,406-11,413. doi: 10.1029/2018GL079037

Schmidt, J. M., Flatau, P. J., \& Yates, R. D. (2014). Convective cells in altocumulus observed with a high-resolution radar. Journal of the Atmospheric Sciences, 71 (6), 2130-2154. doi: 10.1175/JAS-D-13-0172.1

Silber, I., Verlinde, J., Cadeddu, M., Flynn, C. J., Vogelmann, A. M., \& Eloranta, E. W. (2019). Antarctic cloud macrophysical, thermodynamic phase, and atmospheric inversion coupling properties at mcmurdo station - part ii: Radiative impact during different synoptic regimes. Journal of Geophysical Research: Atmospheres, 124(3), 1697-1719. doi: 10.1029/2018JD029471

Smith, A. J., Larson, V. E., Niu, J., Kankiewicz, J. A., \& Carey, L. D. (2009). Processes that generate and deplete liquid water and snow in thin midlevel mixed-phase clouds. Journal of Geophysical Research: Atmospheres, 114(D12). doi: $10.1029 / 2008 J D 011531$

Sotiropoulou, G., Sedlar, J., Forbes, R., \& Tjernström, M. （2016). Summer arctic clouds in the ecmwf forecast model: an evaluation of cloud parametrization schemes. Quarterly Journal of the Royal Meteorological Society, 142(694), 387-400. doi: 10.1002/qj.2658

Sotiropoulou, G., Vignon, E., Young, G., Morrison, H., O'Shea, S. J., Lachlan-Cope, T.,... Nenes, A. (2020). Secondary ice production in antarctic mixed-phase clouds: an underappreciated process in atmospheric models. Atmos Chem Phys Discuss, under review. doi: 10.5194/acp-2020-328

Stevens, B. (2002). Entrainment in stratocumulus-topped mixed layers. Quar- 
terly Journal of the Royal Meteorological Society, 128(586), 2663-2690. doi: 10 $.1256 /$ qj. 01.202

Thompson, G., Field, P. R., Rasmussen, R. M., \& Hall, W. D. $\quad$ (2008). $\quad$ Explicit forecasts of winter precipitation using an improved bulk microphysics scheme. part ii; implementation of a new snow parametrization. Mon Weather Rev, 136(5095). (doi:10.175/2008MWR2387.1)

Uetake, J., Hill, T. C. J., Moore, K. A., DeMott, P. J., Protat, A., \& Kreidenweis, S. M. (2020). Airborne bacteria confirm the pristine nature of the southern ocean boundary layer. Proceedings of the National Academy of Sciences. doi: $10.1073 /$ pnas. 2000134117

Varma, V., Morgenstern, O., Field, P., Furtado, K., Williams, J., \& Hyder, P. (2020). Improving the southern ocean cloud albedo biases in a general circulation model. Atmospheric Chemistry and Physics, 20(13), 7741-7751. Retrieved from https://www.atmos-chem-phys.net/20/7741/2020/ doi: 10.5194/acp-20-7741-2020

Vergara-Temprado, J., Miltenberger, A. K., Furtado, K., Grosvenor, D. P., Shipway, B. J., Hill, A. A., ... Carslaw, K. S. (2018). Strong control of southern ocean cloud reflectivity by ice-nucleating particles. Proceedings of the National Academy of Sciences, 115(11), 2687-2692.

Vignon, E., Besic, N., Jullien, N., Gehring, J., \& Berne, A. (2019). Microphysics of snowfall over coastal East Antarctica simulated by Polar WRF and observed by radar. J Geophys Res Atmos. doi: 10.1029/2019JD031028

Vignon, E., Hourdin, F., Genthon, C., Van de Wiel, B. J. H., Gallée, H., Madeleine, J.-B., \& Beaumet, J. (2018). Modeling the dynamics of the atmospheric boundary layer over the Antarctic Plateau with a general circulation model. $\quad$ Journal of Advances in Model Earth Systems, 10, 98-125. (10.1002/2017MS001184)

Vignon, E., Picard, G., Durán-Alarcón, C., Alexander, S. A., Gallée, H., \& Berne, A. (2020). Gravity wave excitation during the coastal transition of an extreme katabatic flow in antarctica. J Atmos Sci. doi: 10.1175/JAS-D-19-0264.1

Vignon, E., Traullé, O., \& Berne, A. (2019). On the fine vertical structure of the low troposphere over the coastal margins of east antarctica. Atmospheric Chemistry and Physics, 19(7), 4659-4683. doi: 10.5194/acp-19-4659-2019 
Wille, J. D., Favier, V., Dufour, A., Gorodetskaya, I. V., Turner, J., Agosta, C., \&

Codron, F. (2019). West antarctic surface melt triggered by atmospheric rivers. Nature Geoscience, 12(11), 911-916.

Wilson, T. H. (2015). The evolution and life cycle of valley cold pools (Doctoral dissertation, University of California, Los Angeles). Retrieved from http:// escholarship.org/uc/item/44c4k8gh

Young, G., Lachlan-Cope, T., O'Shea, S. J., Dearden, C., Listowski, C., Bower, K. N., .. Gallagher, M. W. (2019). Radiative effects of secondary ice enhancement in coastal antarctic clouds. Geophysical Research Letters, 46(4), 2312-2321. doi: 10.1029/2018GL080551

Zelinka, M. D., Myers, T. A., McCoy, D. T., Po-Chedley, S., Caldwell, P. M., Ceppi, P., .. Taylor, K. E. (2020). Causes of higher climate sensitivity in cmip6 models. Geophysical Research Letters, 47(1), e2019GL085782. doi: 10.1029/2019GL085782 